\title{
Climatologically Significant Effects of Space-Time Averaging in the North Atlantic Sea-Air Heat Flux Fields
}

\author{
SERGEY K. GuleV \\ P. Shirshov Institute of Oceanology, Moscow, Russia, and Institut fuer Meereskunde, Kiel, Germany
}

(Manuscript received 8 December 1995, in final form 11 March 1997)

\section{ABSTRACT}

\begin{abstract}
Differences between "classical" and "sampling" estimates of mean climatological heat fluxes and their seasonal and interannual variability are considered on the basis of individual marine observations from the Comprehensive Ocean-Atmosphere Data Set. Calculations of fluxes were done for intramonthly averaging and for $1^{\circ}-5^{\circ}$ spatial averaging. Sampling estimates give in general $10 \%$ to $60 \%$ higher values of fluxes than do classical estimates. Spatial averaging has a larger effect than temporal averaging in the Tropics and subtropics, and temporal averaging is more effective than spatial averaging in midlatitudes. The largest absolute differences between sampling and classical estimates of fluxes are observed in middle latitudes, where they are 15 to 20 $\mathrm{W} \mathrm{m} \mathrm{m}^{-2}$ for sensible heat flux and 50 to $70 \mathrm{~W} \mathrm{~m}^{-2}$ for latent heat flux. Differences between sampling and classical estimates can change the annual cycle of sea-air fluxes. There is a secular tendency of increasing "samplingto-classical" ratios of $1 \%$ to $5 \%$ decade $^{-1}$ over the North Atlantic. Relationships between sampling-to-classical ratios and parameters of the sea-air interface, the number of observations, and the spatial arrangement of samples are considered. Climatologically significant differences between sampling and classical estimates are analyzed in terms of the contribution from different covariances between individual variables. The influence of different parameterizations of the transfer coefficients on sampling minus classical differences is considered. Parameterizations that indicate growing transfer coefficients with wind speed give the larger sampling minus classical differences in comparison with those based on either constant or decreasing with wind coefficients. Nevertheless, over the North Atlantic midlatitudes, all parameterizations indicate significant sampling minus classical differences of about several tens of watts per square meter. The importance of differences between sampling and classical estimates for the evaluation of meridional heat transport shows that differences between sampling and classical estimates can lead to $0.5-1-\mathrm{PW}$ differences in meridional heat transport estimates.
\end{abstract}

\section{Introduction}

During the last 2 decades, different authors have produced many different climatologies of sea-air heat and momentum fluxes in the North Atlantic Ocean (Bunker 1976; Hastenrath and Lamb 1978; Hastenrath 1980; Esbensen and Kushnir 1981; Weare et al. 1981; Lamb and Bunker 1982; Hsiung 1985; Isemer and Hasse 1985, 1987; Oberhuber 1988; Bottomley et al. 1990; da Silva et al. 1994; Gulev 1995a; Hasse and Lindau 1997). These climatologies indicate a very wide range of estimates, which results from the use of different datasets and different parameterizations, from different approaches to correct systematic biases, from different Beaufort scales used to convert estimates of Beaufort force to wind speed, and from the use of the so-called sampling or classical methods to calculate averaged fluxes. When different flux climatologies are compared,

Corresponding author address: Dr. Sergey K. Gulev, P. Shirshov Institute of Oceanology, RAS, 23 Krasikova Str., 117218 Moscow, Russia.

E-mail: rocc@ sovam.com all of these differences are combined, and there is no way of knowing which estimate, if any, is correct. Gulev (1995a) compared different datasets using identical parameterizations and different parameterizations applied to the same data, and found that the larger differences in estimates resulted from different schemes rather than from different datasets. Recently Kent and Taylor (1995) made a comprehensive comparison of different sensible and latent heat flux climatologies in the North Atlantic. They studied precisely different sources of biases in estimates (Kent et al. 1993) and found the choice of transfer coefficients and the method of calculating averaged fluxes to be the most important contributors to differences between climatologies.

With the present level of computer power and data availability, it is not difficult to produce sampling climatologies. At the same time, heat and momentum flux calculations in models are always based on gridded data and, therefore, should take into account the effect of averaging. The latter is especially important for the validation of coupled ocean-atmosphere models, for which surface fluxes are of highest priority (Gleckler and Weare 1995). Moreover, some climatologies of individual variables were either originally only available in the 
form of gridded monthly averages or the original information was lost (e.g., Budyko 1963), and any comparative assessments cannot avoid the effect of averaging. Thus, the problem of the influence of averaging on sea-air flux estimates is still important, and we expect that it will remain important in the future. We attempt in this study to consider the significance of differences between the "classical" and "sampling" methods for estimates of mean climatological fluxes and their seasonal and interannual variability on the basis of individual marine observations, available from the Comprehensive Ocean-Atmosphere Data Set (COADS) collection.

\section{Data}

In this study, we used COADS (Slutz 1985) in the form of compressed marine reports (CMR-5), which contain individual observations of basic quantities at sea-air interface, collected by merchant and research vessels. We used COADS release 1 for the period from 1950 to 1979 . We decided not to use the recently available COADS release 1a for the period 1980-93 (Woodruff et al. 1993), which provides long marine reports (LMR-6). First, there are still many questions about the data control in COADS release 1a. A number of attempts to use even the Monthly Summary Trimmed Groups (MSTGs) version of COADS release 1a show questionable reliability of the results (Gulev 1995a,b; Isemer 1995). Secondly, data collection in COADS release 1a for the 1980s and early 1990s is still poor in comparison with COADS release 1 for earlier decades. Although there has been a general tendency for the number of marine observations to decrease since the late 1960s, there are also many data for the 1980s, 1990s, and even the late 1970s, which are not yet incorporated into the COADS collection. Figure 1 shows changes with time of the number of COADS CMR (for release 1a, LMR) for the whole North Atlantic. For the 1980s, the number of reports are half the number in previous decades. For the midlatitudes (Fig. 1), the decrease can be even more remarkable. At the same time, space-time averaging effects are very sensitive to the homogeneity of sampling, and for the data from the 1980s and 1990s, we will obviously have incomplete sampling in comparison with earlier decades. Thus, we decided to avoid the possibility of merging CODAS releases 1 and $1 \mathrm{a}$ and will use only release 1 for the period 1950-79. Basic meteorological variables (SST, air temperature, wind speed and direction, dewpoint temperature, cloudiness, and sea leve pressure) were extracted from COADS CMR and decoded. We made a quality control of the data, according to COADS quality flags, also available from COADS CMR. We have excluded from our consideration some areas north of $60^{\circ} \mathrm{N}$ in the northwest Atlantic to avoid inhomogeneity of sampling in space.

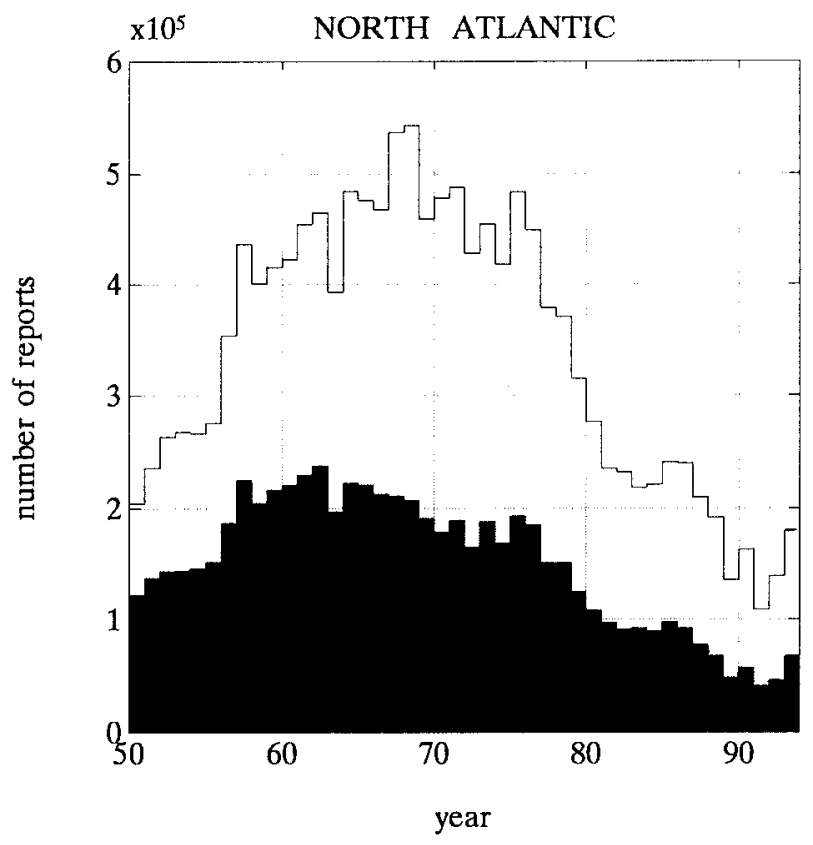

FIG. 1. Changes of the number of reports without missing basic meteorological variables in the whole North Atlantic (white area) and in the North Atlantic midlatitudes (black area).

\section{Computation of sampling and classical estimates of fluxes}

To calculate sea-air heat fluxes, be it a sampling or a classical estimate, we used the bulk aerodynamic formulas in the following form:

$$
Q_{H}=C_{P} \rho_{a} C_{T} V \delta T, \quad Q_{E}=L \rho_{a}(0.622 / P) C_{E} V \delta e,
$$

where $Q_{H}$ is the sensible heat flux; $Q_{E}$ is the latent heat flux; $\delta T=T_{w}-T_{a} ; \delta \mathrm{e}=e_{o}-e_{z} ; T_{w}$ is sea surface temperature; $T_{a}$ is air temperature; $e_{z}$ is water vapor pressure; $e_{o}$ is saturation vapor pressure, which results from $T_{w} ; V$ is wind speed; $\rho_{a}$ is air density; $\mathrm{C}_{\mathrm{P}}$ is the specific heat of air at constant pressure; $L$ is the latent heat of evaporation of water; and $C_{T}$ and $C_{E}$ are the transfer coefficients. There are many methods to estimate these coefficients. Some of them are based on direct flux measurements from platforms or ships (Hasse 1970; Pond et al. 1974; Smith and Banke 1975; Friehe and Schmitt 1976; Large and Pond 1981, 1982; Smith 1980,1988 ) or on a semiempirical theory of the surface layer (Kondo 1975; Liu et al. 1979; Ariel et al. 1981). Others were obtained as appropriate summaries of known estimates (Bunker 1976) or from different inverse principles, which are used to reach known heat and water balances of the global World Ocean (Budyko 1963, 1974), individual ocean basins (Isemer and Hasse 1987; Isemer et al. 1989), or enclosed seas (Bunker et al. 1982; Efimov et al. 1985). The choice of the scheme is a key question for the calculations of sea-air exchange climatologies (Kent and Taylor 1995). Blanc (1985) compared a large number of schemes on the basis of 1 
year of observations at Ocean Weather Station (OWS) $\mathrm{C}\left(52.5^{\circ} \mathrm{N}, 35.5^{\circ} \mathrm{W}\right)$ and found remarkably pronounced scheme-to-scheme variations that coincides with comparisons of different schemes for the whole North Atlantic (Gulev 1995a; Kent and Taylor 1995).

In our case, when studying the impact of space-time averaging on climatological fluxes and their variations, it is important to ensure comparability of sampling and classical estimates and to select a single scheme, which will be applied to both estimates. This scheme, on one hand, should give realistic values of transfer coefficients and, on the other hand, should provide the wind speed and stability dependence of the coefficients in order to study their covariances with individual variables. We used the Ariel et al. (1981) scheme, based on a semiempirical model of the marine atmospheric surface layer. The Ariel et al. (1981) formulation is very close to the Liu et al. (1979) method, although for moderate winds, Ariel et al.(1981) gives a positive correlation of coefficients with wind speed and Liu et al. (1979) gives slightly negative correlation. The comparison of Ariel's (1981) scheme with others and its application to the North Atlantic heat fluxes is given in Gulev (1994, 1995a). One can still ask whether differences between sampling and classical methods depend on the choice of bulk parameterization. We will address this problem in the discussion section below, comparing the sensitivity of different schemes to averaging effects.

When formula (1) is applied to individual observations of meteorological variables, mean fluxes can be easily obtained by taking averages over individual estimates (the so-called sampling method). When individual observations of meteorological quantities are averaged first and formula (1) is applied to their temporal or spatial means, this is the so-called classical method. Esbensen and Reynolds (1981) reasonably argue that for proper use of the sampling method, observations of the wind temperatures and humidity are required to be taken simultaneously in space and time. Voluntary observing ships (VOS) instrumental measurements provide usually observations averaged over $10 \mathrm{~min}$ (or several hundred meters) (Kent et al. 1991, 1993). Moreover it is not clear whether Beaufort estimates of wind and bucket SST measurements can be accepted as averaged over the same time interval. Thus, using VOS, we assume sampling observations to be averaged within 10 min in time and several hundred meters in space. The following equation gives the ratio between sampling and classical estimates:

$$
\begin{aligned}
\left\langle C_{T} V \delta T\right\rangle= & \left\langle C_{T}\right\rangle\langle\underset{1}{ }\rangle\langle\delta T\rangle+\left\langle C_{T}\right\rangle\left\langle V^{\prime} \delta T^{\prime}\right\rangle \\
& +\left\langle C_{T}^{\prime} \delta T^{\prime}\right\rangle\langle V\rangle+\left\langle C_{T}^{\prime} V^{\prime}\right\rangle\langle\delta T\rangle \\
& \\
& +\underset{5}{\left\langle C_{T}^{\prime} V^{\prime} \delta T^{\prime}\right\rangle,}
\end{aligned}
$$

where \langle\rangle is the averaging operator, which corresponds to either temporal, spatial, or joint space-time averaging. Equation (2) is given for sensible heat flux, but similar equations can be written for latent heat flux. Term 1 on the right-hand side corresponds to the product of mean values of wind speed, sea-air temperature difference, and transfer coefficient. Terms 2-5 show covariances of the wind speed, sea-air temperature difference, and transfer coefficient, and also their triple covariance. The contributions of these covariances result from the correlation between individual variables. Recently, Ledvina et al. (1993) suggested the introduction into (2) of an additional term, which results from the difference between $C_{T}$ calculated from average conditions and the average of varying coefficients. The contribution of this term, which is not very significant (Ledvina 1993; Gulev 1994) will be displayed in the discussion section. Additional terms would appear in (2) if the nonlinearity of the air density in (1) were considered; however, they would not contribute significantly, with some rare exceptions in the eastern tropical and subtropical areas where this nonlinearity can account for $3 \%$ to $5 \%$ of sampling minus classical differences, although these differences are rather small there.

Comparisons of sampling and classical estimates of fluxes are given in many articles. Most consider temporal averaging (Kraus and Morrison 1966; Robinson 1966; Kondo 1972; Fissel et al. 1977; Esbensen and Reynolds 1981; Bortkovskiy 1983; Larin and Panin 1985; Hanawa and Toba 1987; Gulev and Ukrainsky 1989; Ledvina et al. 1993; Gulev 1994; Josey et al. 1995; Staneva et al. 1995; Zhang 1995). Some estimates indicate that higher fluxes are calculated with the sampling method. Differences for monthly averaging range from several percent to several tens of percent. At the same time, Esbensen and Reynolds (1981), Simmonds and Dix (1989), and Zhang (1995) found sampling and classical estimates to be close to each other. Josey et al. (1995) even found that classical fluxes overestimate sampling values by nearly $10 \%$. This overestimation can result from specific weather conditions, which could be responsible for negative correlations between wind speed and humidity differences primarily in the eastern Atlantic (Josey 1995). Similar features for triple covariances in (2) were found in Gulev (1994).

Effects of purely spatial averaging were studied in Gulev (1994) and were found to be significant in the northwest Atlantic midlatitudes. At the same time, in computing flux fields, one will deal with joint spacetime (intrabox) averaging, and the coupled effect could be stronger than that from purely temporal or spatial averaging. Garstang (1965) and Reed (1985) studied these effects for the tropical Atlantic and the tropical Pacific, respectively, and found sampling estimates to be $2 \%$ to $10 \%$ higher. Considerable efforts were taken to evaluate the so-called areally averaged fluxes over land (Mahrt 1987; Mason 1988; Claussen 1990, 1991), where these fluxes could be parameterized using effec- 
tive roughness and, therefore, the effective drag coefficient. There are several model studies comparing simulated sampling and classical fluxes (Gavrilin and Monin 1969; Adamec and Elsbery 1984; Simmonds and Dix 1989), which result from the space-time averaging, although the authors mainly discuss temporal effects. Nevertheless, the significance of space-time averaging for climatological flux fields and their variability is still poorly understood, although we can expect that the effects of intrabox averaging will have profound implications for climatological fluxes and can be remarkably variable in space and time.

In order to evaluate the differences between sampling and classical estimates, we first computed fluxes (1) for the North Atlantic Ocean on the basis of individual reports available from the COADS CMR collection and obtained averaged fluxes for individual months over the $30-\mathrm{yr}$ period. We then produced a number of monthly mean climatologies of basic variables with a spatial resolution of $1^{\circ}$ to $5^{\circ}$ using exactly the same individual reports. On the basis of these climatologies, sea-air heat fluxes were recomputed with the use of formula (1), which gave us the opportunity to study the patterns of the ratios between sampling and classical estimates:

$$
\begin{aligned}
& \xi_{H}(r)=\left\langle C_{T} V \delta T\right\rangle_{r} /\left\langle C_{T}\right\rangle_{r}\langle V\rangle_{r}\langle\delta T\rangle_{r}, \\
& \xi_{E}(r)=\left\langle C_{E} V \delta e\right\rangle_{r} /\left\langle C_{E}\right\rangle_{r}\langle V\rangle_{r}\langle\delta e\rangle_{r},
\end{aligned}
$$

where operator \langle\rangle$_{r}$ corresponds to intramonthly averaging within the box of size $r$. One can reasonably argue that the coefficients given by (3) cannot be adequately considered for the Tropics and the high latitudes and should have a pronounced latitudinal dependence merely from the smaller size of 1 longitudinal degree in the north in comparison with the equatorial area. This is not only a problem for the comparison of sampling and classical estimates of fluxes, but also for the creation of gridded (boxed) climatologies in general. For example, Bunker (1976) used for his North Atlantic climatology special, irregularly shaped boxes in order to provide homogeneity of hydrologic conditions and adequate sampling for each box.

Moreover, in the general case, even an $n$ by $n \mathrm{~km}$ box has an uncertain estimate of the spatial scale of averaging. For example, in order to study spatial averaging in the northwest Atlantic, we used circular networks (Gulev 1994). However, all known climatologies [except for Bunker's (1976), although it is mainly used these days in the regular $1^{\circ}$ form, as gridded by Isemer and Hasse $(1985,1987)]$ were produced for squares and estimated in degrees of latitude and longitude. Numerical models also primarily deal with a regular grid. Thus, to meet the needs of users of climatologies and modelers, we will consider our estimates for boxes also, estimated in degrees of latitude and longitude.

An important question for the study of spatial and temporal averaging effects is the choice of scalar or vector averaging for the calculation of wind. The choice is especially significant for wind stress estimates (Saunders 1976; Wright and Thompson 1983; Thompson et al. 1983; Marsden and Pond 1983; Hanawa and Toba 1987; Lander et al. 1989; Weare 1989). Most results indicate that the differences between scalar and vector averaging are high, although both methods of averaging are still used for different needs. Esbensen and Reynolds (1981) recommend the use of wind roses with a certain number of wind direction categories and wind speed categories for a proper calculation of the classical estimates of the wind stress. Wind stress estimates are not considered in this paper. For the comparisons of sampling and classical estimates of sensible and latent heat fluxes, we used scalar-averaged wind.

Another important problem is the possible dependence of differences between sampling and classical estimates of fluxes on the completeness of sampling within individual months and boxes and on the intrabox network type. Sampling minus classical differences can vary significantly with the number of samples, even if mean values of variables and, therefore, classical estimates of fluxes are occasionally close to each other in the case of remarkable incomplete sampling and in the case of oversampling. The decreasing number of samples below a certain limit has the effect of filtering out synoptic and mesoscale variability on small spacetimescales. That can significantly underestimate differences between sampling and classical estimates because short-term variability contributes significantly to covariances 2-5 in (2) (Gulev 1994). Uncertainties related to inadequate sampling were studied by Fissel et al. (1977), Weare and Strub (1981), Weare (1989), Legler (1991), and Cayan (1992a). For the midlatitudes 50 to 100 samples month $^{-1}$ are required to guarantee completeness (Legler 1991; Cayan 1992a), although for the Tropics and the subtropics, this limit could be several times lower (Weare and Strub 1981). To avoid very incomplete sampling, we considered only cases with more than 12 observations month ${ }^{-1}$ for a $2^{\circ}$ box and with more than 30 observations in a $5^{\circ}$ box. For some areas that have many observations, we studied the influence of the number of samples on the results. The influence of the intrabox network type (arrangement of samples) on standard errors of the monthly mean wind speed has been studied by Morrissey and Maliekal (1995). They found that the so-called linear network, which aligned along the major axis of the spatial correlation function, provides standard errors three to five times higher than a random network. This problem is serious only in boxes greater than $4^{\circ}$. COADS data provide a wide range of networks for different regions of the North Atlantic. We made comparisons of the effects of averaging for different network types in some areas.

\section{Results}

a. Climatological means

Most results presented in our study will refer to the $5^{\circ}$ and $2^{\circ}$ monthly averaging, although calculations were 

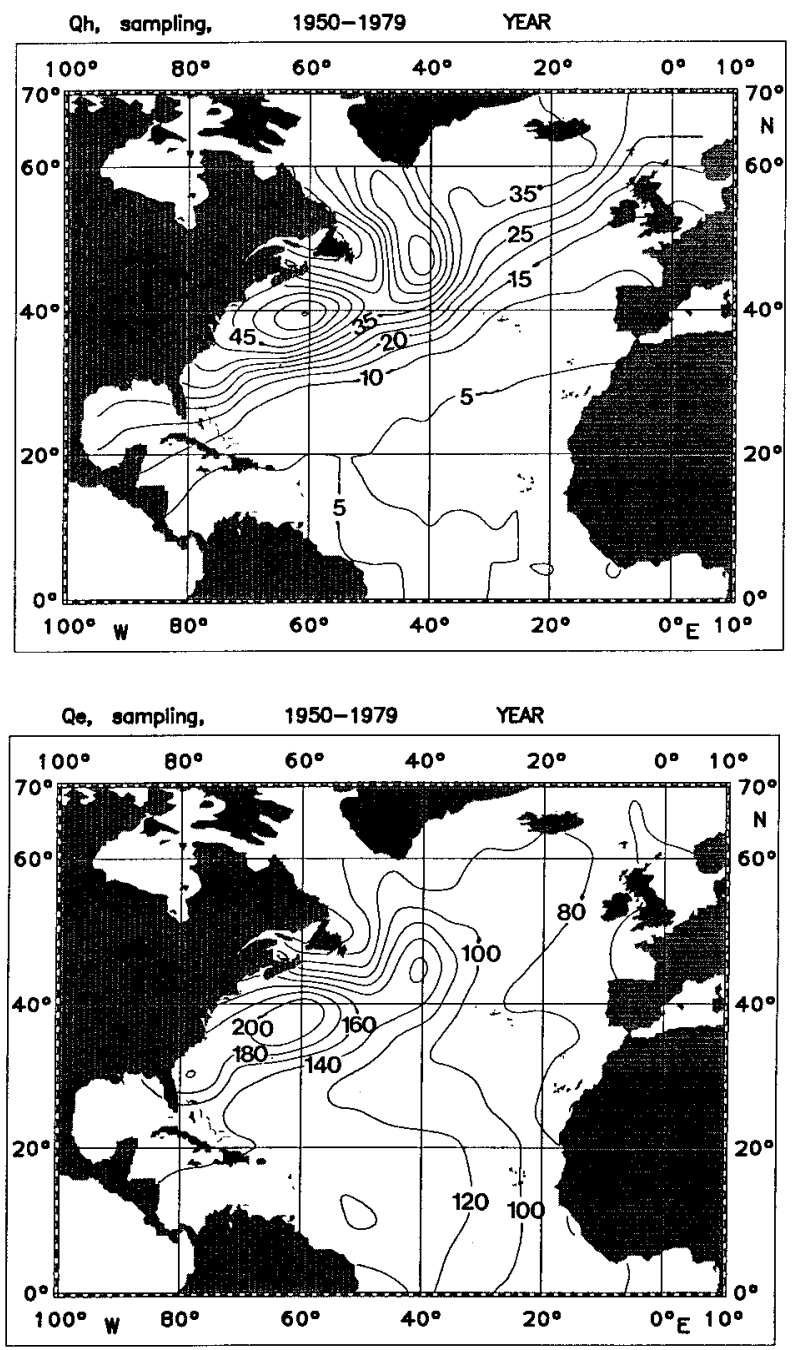

FIG. 2. Climatological fields of sensible heat flux and latent heat flux $\left(\mathrm{W} \mathrm{m}^{-2}\right)$, computed with the sampling method for the North Atlantic Ocean for 1950-79.

also done for $1^{\circ}, 3^{\circ}$, and $4^{\circ}$ averaging. Figure 2 shows climatological fields of sensible and latent heat flux, computed with the sampling method for the North Atlantic for the period 1950-79. We show these charts here to give a reference level for later results, which will be presented mainly as ratios between different estimates, rather than to discuss the reliability of these climatological estimates. The climatological flux fields in Fig. 2 display known patterns of spatial variability (Bunker 1976; Hastenrath and Lamb 1978; Esbensen and Kushnir 1981; Isemer and Hasse 1987; Oberhuber 1988; da Silva et al. 1994; Gulev 1995a; Hasse and Lindau 1997). Our sensible heat fluxes are slightly lower than the estimates of Bunker (1976) and Isemer and Hasse (1987), although they are in good agreement with other climatologies. Latent heat flux in the Tropics is smaller by 10 to $30 \mathrm{~W} \mathrm{~m}^{-2}$ than those obtained by Hasse

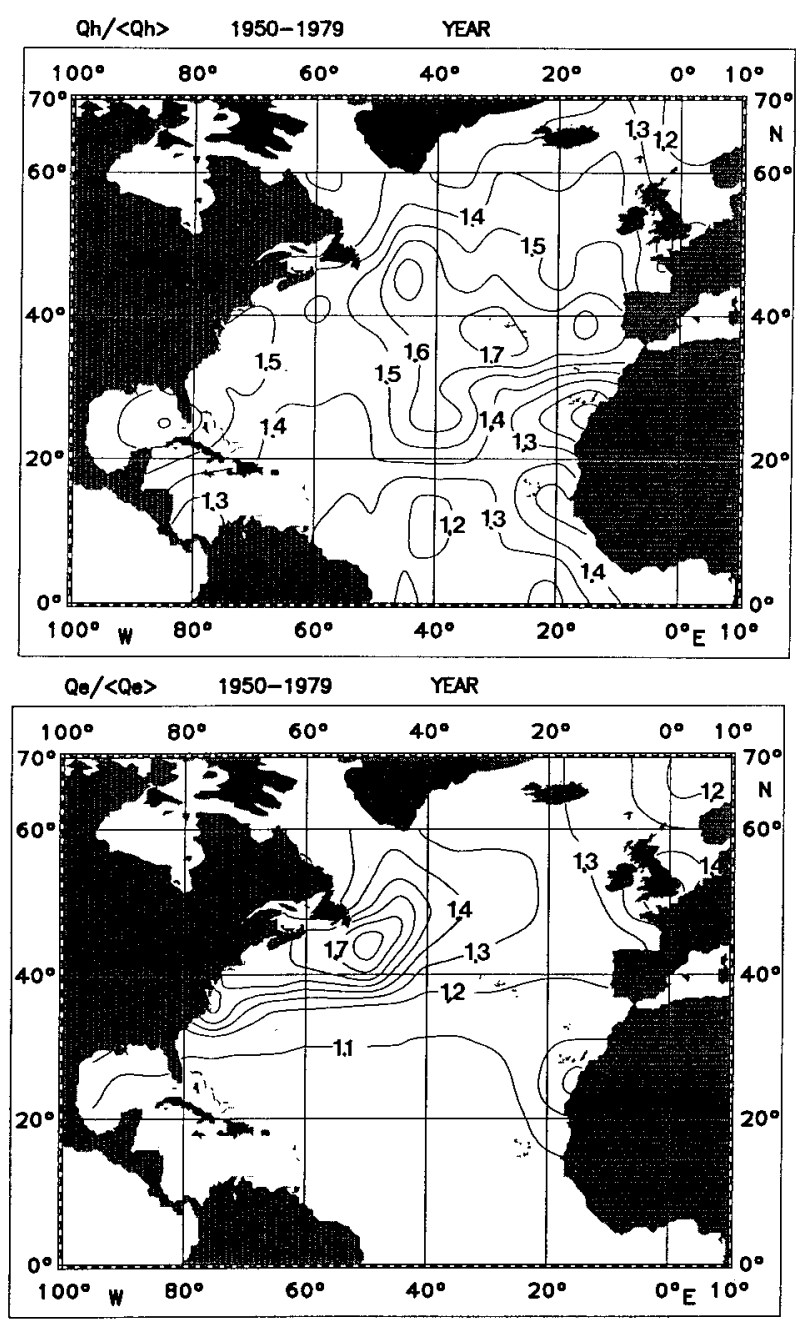

FIG. 3. Climatological maps of sampling-to-classical ratios for $5^{\circ}$ spatial averaging for sensible heat flux and latent heat flux.

and Lindau (1996), although it agrees quite well with them in the middle and high latitudes.

Climatological maps of the ratios in (3) between sampling and $5^{\circ}$ classical estimates are given in Fig. 3 for sensible and latent heat flux. Hereafter, these ratios were computed on the basis of climatological annual or seasonal flux fields. The alternative way (to compute ratios for individual months and years and then to take an average) is much more sensitive to division by small values of fluxes, which reasonably appear in the Tropics, at least for sensible heat flux. Sampling estimates give in general remarkably higher values of fluxes than classical estimates. Spatial patterns of $\xi_{H}^{5}$ and $\xi_{E}^{5}$ are different, especially in the midlatitudes. The largest differences between sampling and classical estimates of sensible heat flux occur in the midlatitude central and east Atlantic south of $45^{\circ} \mathrm{N}$, where they range from 1.6 to 1.8. Another local maximum is located in the north $\mathrm{Ca}$ ribbean Sea and the subtropical west Atlantic. The smallest ratios, from 1.0 to 1.2, are found in the Tropics. 


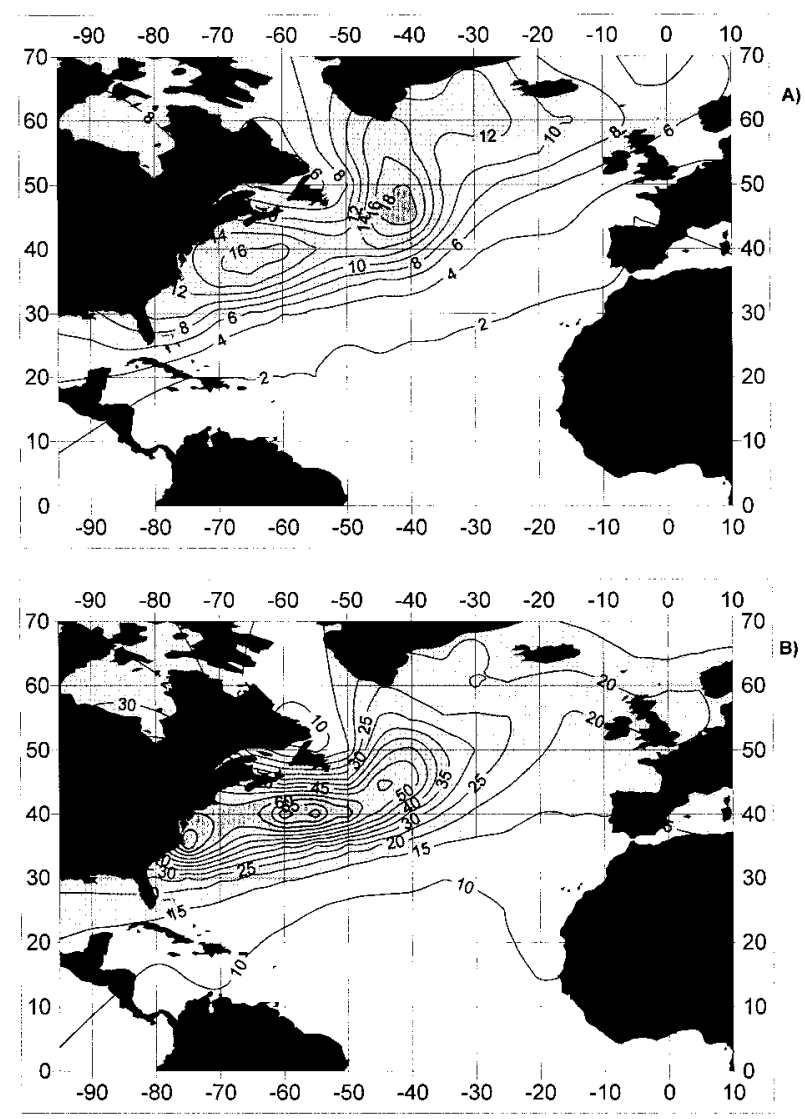

FIG. 4. Climatological maps of absolute sampling minus classical differences $\left(\mathrm{W} \mathrm{m}^{-2}\right)$ for $5^{\circ}$ averaging for (a) sensible heat flux and (b) latent heat flux.

If we consider the $\xi_{E}^{5}$ coefficient (Fig. 3), there is a pronounced maximum of about 1.6-1.8 southeast of Newfoundland and a sharp decrease of the difference between sampling and classical estimates in the subtropics and Tropics, where $\xi_{E}^{5}$ ranges from 1.0 to 1.1. The maxima of the ratios in (3) do not coincide with the climatological maxima of the fluxes. The midlatitudinal maximum of $\xi_{E}^{5}$ is shifted to the northwest from the maximum of $Q_{E}$ and is located in an area of relatively small latent heat fluxes.

When we discuss sampling-to-classical ratios, we have to consider them in view of the magnitude of the absolute values of fluxes. This is especially important for the tropical sensible heat flux, which varies within the range from 1 to $10 \mathrm{~W} \mathrm{~m}^{-2}$, and even $\xi_{H}=2$ can have an effect that is within the accuracy of climatological estimates. Figure 4 displays the absolute differences between the sampling and classical estimates for the sensible heat flux and the latent heat flux. Absolute error for the sensible heat flux is significant in the middle and high latitudes. The largest sampling minus classical differences occur in the northwest Atlantic, where they vary from 16 to $20 \mathrm{~W} \mathrm{~m}^{-2}$. At the same time, in the Tropics, sampling minus classical differences are small
TABLE 1. Climatological mean sampling-to-classical ratios of the different sea-air fluxes for different spatial averaging.

\begin{tabular}{lccccc}
\hline \hline Flux & $1^{\circ}$ & $2^{\circ}$ & $3^{\circ}$ & $4^{\circ}$ & $5^{\circ}$ \\
\hline$Q_{\mathrm{H}}$ & 1.25 & 1.29 & 1.33 & 1.38 & 1.40 \\
$Q_{\mathrm{E}}$ & 1.13 & 1.15 & 1.18 & 1.20 & 1.20 \\
\hline
\end{tabular}

and are usually less than $2 \mathrm{~W} \mathrm{~m}^{-2}$. If we consider the absolute error of the estimates of the latent heat flux (Fig. 4), there is a pronounced maximum in the Gulf Stream area ranging from 60 to $70 \mathrm{~W} \mathrm{~m}^{-2}$. In the North Atlantic midlatitudes sampling minus classical differences for the latent heat flux are always higher than 15 $\mathrm{W} \mathrm{m}^{-2}$. Differences smaller than $10 \mathrm{~W} \mathrm{~m}^{-2}$ are obtained in the Tropics, where $\xi_{E}$ is usually smaller than 1.1 (Fig. $3)$.

Table 1 shows sampling-to-classical ratios between climatological means of flux estimates averaged over the North Atlantic. Ratios for $1^{\circ}$ resolution are very close to those for $2^{\circ}$ resolution and primarily demonstrate the effect of temporal averaging. Then ratios increase monotonically up to $4^{\circ}$ resolution, and values for $5^{\circ}$ averaging are very close to $4^{\circ}$ estimates. Taking into account these two definite breaks at $2^{\circ}$ and $4^{\circ}$, we decided to display most results for these two scales of spatial averaging. Figure 5 represents the ratios in (3) for $2^{\circ}$ averaging. If we compare maps of $\xi_{H}^{5}$ and $\xi_{H}^{2}$ coefficients, there are remarkable changes in spatial patterns in the midlatitudes. The area where $\xi_{H}^{2}>1.4$ is aligned from the southwest to the northeast across the North Atlantic. The highest values, of about 1.6, occur at $40^{\circ} \mathrm{N}$. The lowest $\xi_{H}^{2}$ coefficients, of 1.05 to 1.15 , are found in the equatorial area and in the northwest Atlantic high latitudes. Again, as in the case with $5^{\circ}$ resolution, the absolute value of sampling minus classical differences in the Tropics varies within the range of $2 \mathrm{~W} \mathrm{~m}^{-2}$ and is lower than the accuracy of the flux estimates. The location of the maximum of the sampling-to-classical ratio for the latent heat flux (Fig. 5) is close to that for $5^{\circ}$ averaging (Fig. 3), although there is a small shift to the south. Maximum absolute sampling minus classical differences for the latent heat vary from 45 to 60

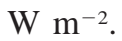

In general, the sampling-to-classical ratios for $2^{\circ}$ averaging and for $5^{\circ}$ averaging are very close to each other in the North Atlantic midlatitudes and in the trade winds zone in the Tropics. Spatial averaging within the range of $5^{\circ}$ is not as important here as temporal averaging, due to a high spatial correlation of synoptic and subsynoptic processes. The major reduction of fluxes between $2^{\circ}$ and $5^{\circ}$ averaging takes place in the midlatitudinal subpolar frontal zone, the subtropical east Atlantic, the Caribbean Sea, and the equatorial area. Spatial averaging has the largest effect in these regions, characterized by spatial inhomogeneity of sea surface temperature.

Spatial inhomogeneity effects may also be related to transient disturbances, such as cold-air outbreaks and 


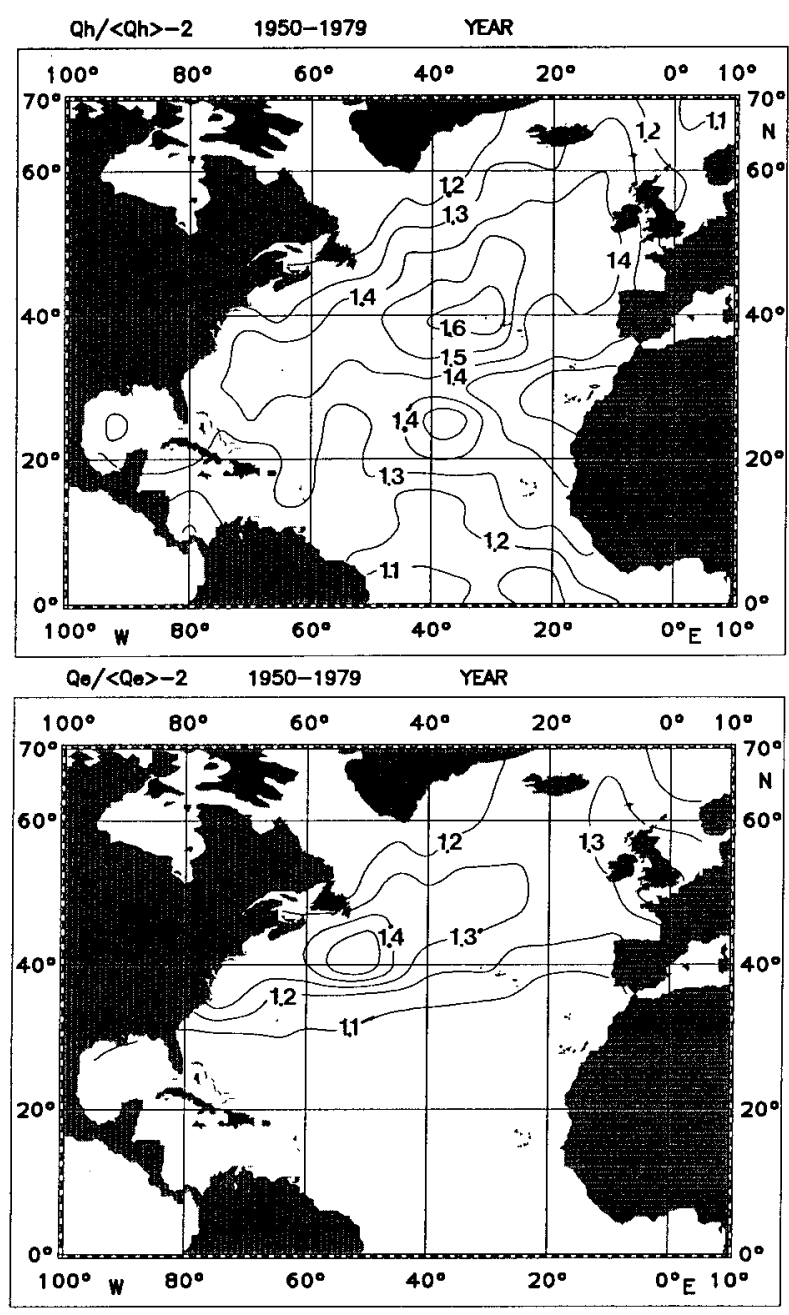

FIG. 5. As in Fig. 3 but for $2^{\circ}$ spatial averaging.

synoptic-scale disturbances (Bane and Osgood 1989; Yau and Jean 1989; Gulev and Tonkacheev 1994). In the western subtropical Atlantic, there could be a partial contribution of hurricanes to spatial averaging effects.

It is interesting to compare our estimates for $2^{\circ}$ averaging with earlier results for temporal averaging, which are mostly obtained on the basis of ocean weather stations' data and short-term series of instrumental measurements. In general, our estimates of sampling-toclassical ratios are slightly higher than the estimates of Gulev (1994) and considerably higher than the estimates of Esbensen and Reynolds (1981), who found the classical estimate to be within $10 \%$ percent of the sampling estimate, where the latter is significantly larger than zero. At the same time, for some locations, we obtained smaller values than were predicted by studies of purely temporal averaging. This underestimation could result from both different time periods of data being used (OWS data are primarily collected for 1948-72) and incomplete sampling in the COADS collection (OWS data are nearly complete and contain usually more than
200 observations month ${ }^{-1}$ ). We will discuss below the possible influence of incomplete sampling on averaging effects. Another possible reason for differences in sampling-to-classical ratios is the use of different parameterizations of the transfer coefficients, which will also be discussed below.

\section{b. Seasonal cycle}

Figure 6 shows annual latitude diagrams of zonal averages of sampling-to-classical ratios for the sensible and latent heat fluxes in the North Atlantic for $5^{\circ}$ and $2^{\circ}$ averaging. The coefficients given by (3) have a pronounced seasonal dependence. For sensible heat flux, the smallest coefficients occur in winter and the maximum $\xi_{H}^{5}$ coefficient appears in summer in the midlatitudes, with values from 1.8 to 2.0. Similar behavior was obtained for temporal averaging in the northwest Atlantic (Gulev 1994). Sensible heat fluxes in summer are quite small over the whole North Atlantic, and differences between sampling and classical estimates are within the accuracy of bulk estimates nearly everywhere. On the diagram of the absolute sampling minus classical differences (Fig. 7a), significant zonal departures are detectable only for late fall, winter, and early spring in the mid- and high latitudes. The highest values of the $\xi_{E}^{5}$ coefficient are observed during the spring and autumn, when they are from $10 \%$ to $20 \%$ higher than in the winter and summer. Absolute error (Fig. 7b) indicates a pronounced annual cycle, with a winter maximum of 50-60 $\mathrm{W} \mathrm{m}^{-2}$ and a summer minimum of $10-$ $15 \mathrm{~W} \mathrm{~m}^{-2}$ in the midlatitudes. The seasonal march of the coefficients in (3) for $2^{\circ}$ averaging (Fig. 6) indicates a general similarity of seasonal dependence to that obtained for $5^{\circ}$ averaging. At the same time, $5^{\circ}$ averaging has a higher effect in summer in the subtropics and a lower effect in winter in high and midlatitudes. The seasonal cycle of the $\xi_{E}^{2}$ coefficient indicates a pronounced midlatitudinal maximum in the summer.

Figure 8 gives seasonal charts of sampling minus classical differences for $5^{\circ}$ averaging for sensible and latent heat fluxes. Due to very small (within $3 \mathrm{~W} \mathrm{~m}^{-2}$ ) summer absolute sampling minus classical differences for sensible heat flux, we show in Fig. 8 only winter values of $C_{P} \rho_{a}\left(\left\langle C_{T} V \delta T\right\rangle-\left\langle C_{T}\right\rangle\langle V\rangle\langle\delta T\rangle\right)$. The largest winter sampling minus classical differences for both sensible and latent heat fluxes are connected with the North Atlantic midlatitudes north of $35^{\circ} \mathrm{N}$ and obviously result from very high synoptic variability in the storm track area. Maximum absolute errors vary from 30 to $40 \mathrm{~W} \mathrm{~m}^{-2}$ for sensible heat flux and from 80 to $110 \mathrm{~W} \mathrm{~m}^{-2}$ for latent heat flux. In the Tropics, absolute winter departures of the sampling fluxes from the classical estimates are within 5 and $10 \mathrm{~W} \mathrm{~m}^{-2}$ for sensible and latent heat fluxes, respectively. The summer maximum of sampling minus classical differences for latent heat flux indicates 20-25 $\mathrm{W} \mathrm{m}^{-2}$ in the northwest Atlantic midlatitudes. 

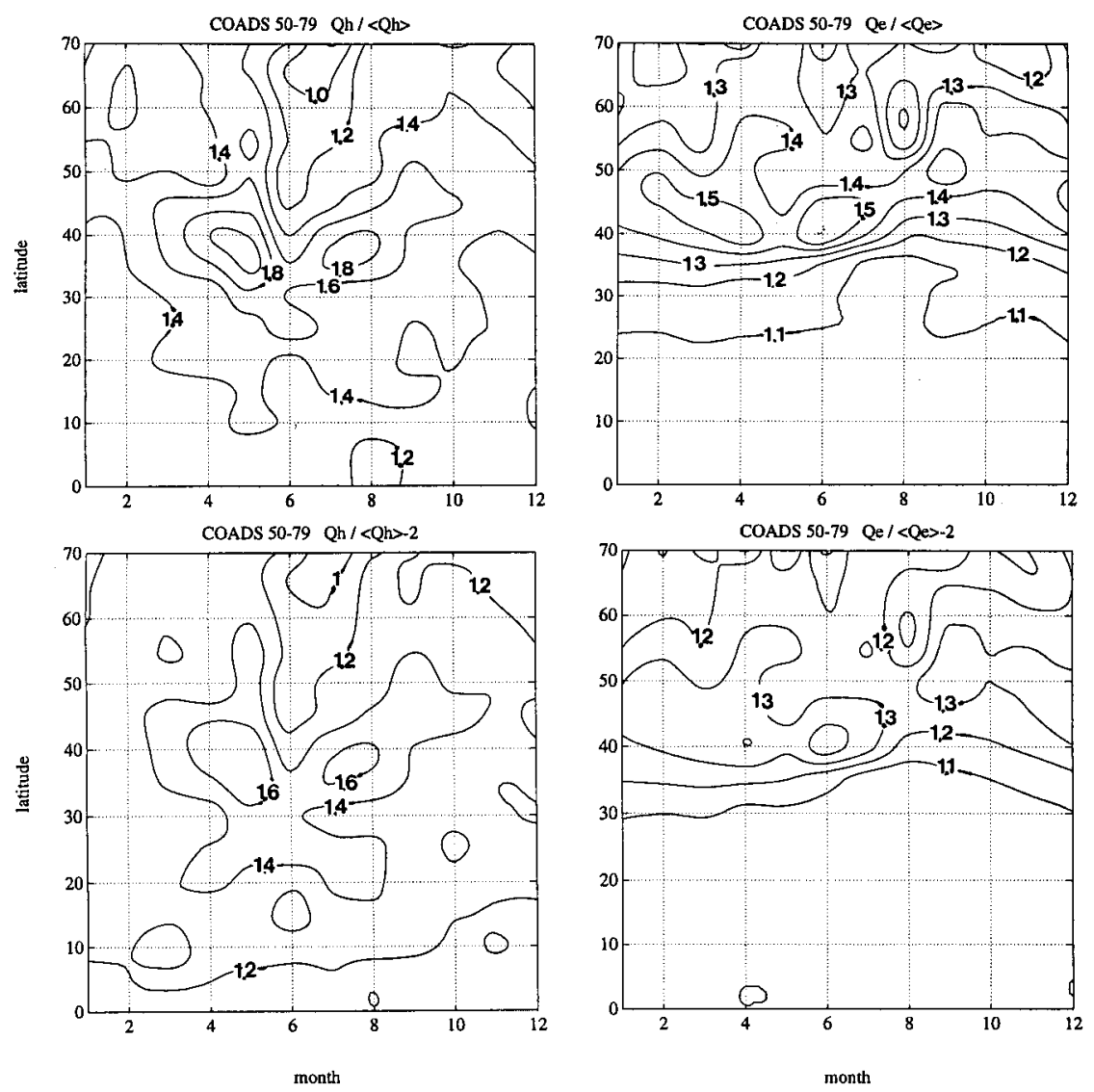

FIG. 6. Annual cycle of zonal averaged sampling-to-classical ratios for $5^{\circ}$ and $2^{\circ}$ spatial averaging for sensible heat flux and latent heat flux.

There is another local maximum in the North Sea, where the absolute error is from 15 to $20 \mathrm{~W} \mathrm{~m}^{-2}$.

Since sampling minus classical differences have a clear seasonal dependence, we expect a significant impact of the averaging effects on the characteristics of the annual cycle of fluxes. Figure 9 shows the ratios between the amplitudes of the annual and semiannual harmonics of the latent heat flux computed from sampling and classical methods. Amplitudes were computed by the harmonical analysis of $30-\mathrm{yr}$ series. Note that, particularly for latent heat, the semiannual harmonic contributes significantly in the Tropics and the high latitudes. Averaging can change the structure of the seasonal cycle significantly. The annual harmonic $A_{12}\left(Q_{E}\right)$ becomes 1.4 to 1.7 times smaller in midlatitudes when computed from classical estimates of fluxes. In the Tropics and subtropics, the reduction of $A_{12}\left(Q_{E}\right)$ ranges from $2 \%$ to $20 \%$. At the same time, the semiannual harmonic can even increase by $10 \%$ to $30 \%$ when computed from classical estimates. Thus the seasonal cycle can be very different for sampling and classical estimates. The annual cycle of the sensible heat flux (not shown here) also indicates differences between the two methods. These differences are even larger than for latent heat flux in the midlatitudes, but are smaller in the Tropics and subtropics.

\section{c. Interannual variability}

Differences between the sampling and classical estimates of fluxes can have significant effects on the longterm variability of air-sea fluxes. Sampling estimates, in contrast to classical estimates, account for the synoptic and mesoscale variability because they include short-term covariances of individual variables. Even if there are significant changes of mean values, changes of short-term covariances (or the intensity of synoptic processes) may not necessarily be significant and vice versa. We computed long-term linear trends of fluxes estimated with sampling and classical methods. We avoid here discussion of these trends and their possible relations to trends in COADS winds. During recent years, there has been considerable debate on the questionable reliability of interdecadal wind speed trends of from 0.1 to $0.5 \mathrm{~m} \mathrm{~s}^{-1}$ decade $^{-1}$ indicated by COADS (Ramage 1984; Peterson and Hasse 1987; Cardone et al. 1990; Lindau et al. 1990; Ward 1992; Isemer 1995; Diaz et al. 1995). For example, Isemer (1995) compared 

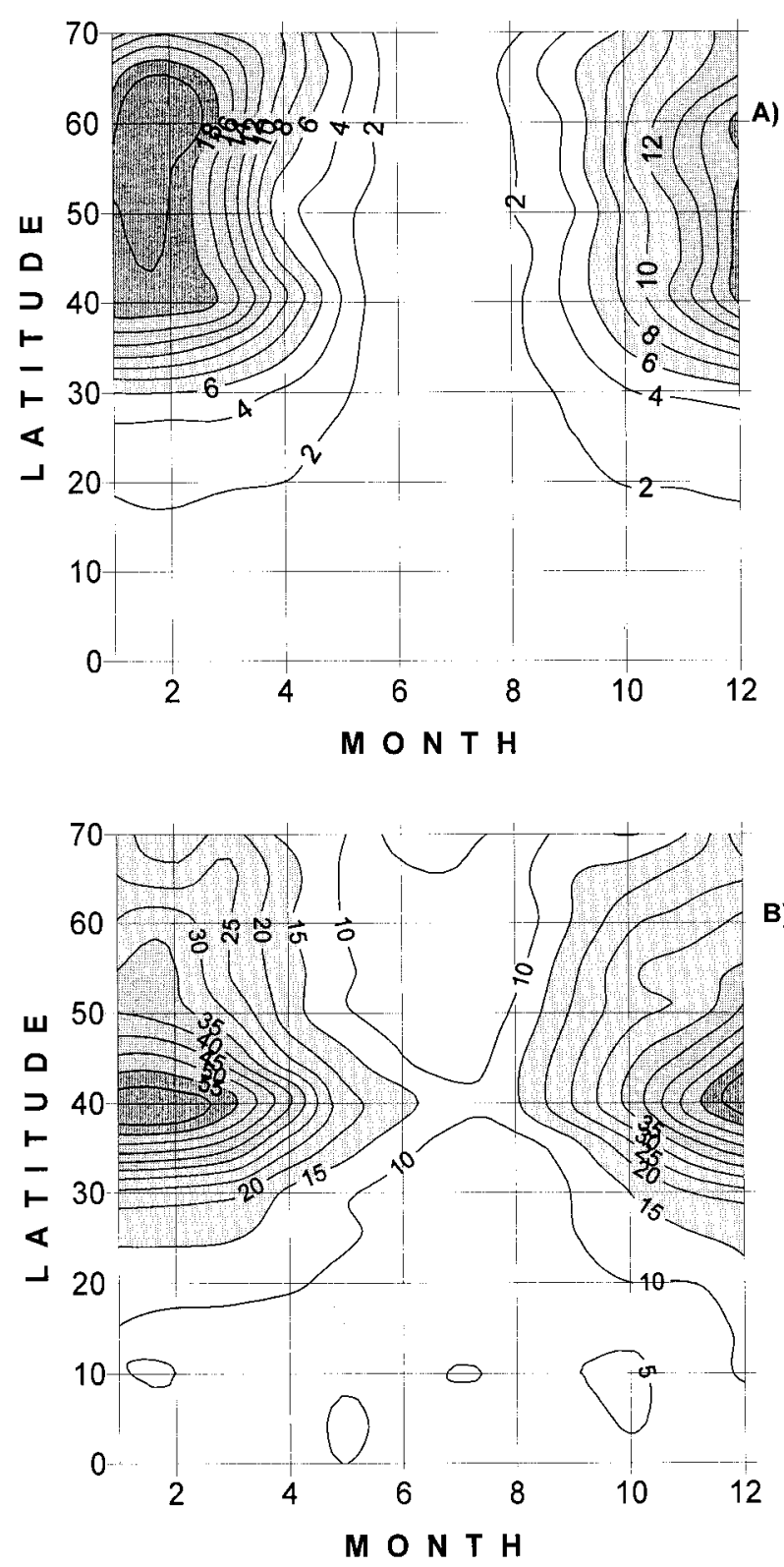

FIG. 7. Annual cycle of zonal averaged sampling minus classical absolute differences $\left(\mathrm{W} \mathrm{m}^{-2}\right)$ for $5^{\circ}$ spatial averaging for (a) sensible heat flux and (b) latent heat flux.

COADS wind trends with those observed at OWSs and found them to be inconsistent. The increase with time of the relative role of anemometer measurements in comparison with Beaufort estimates is considered to be one possible reason for this disagreement, although there are other reasons, which are still poorly understood. Our focal point in this paper is the possible impact of space-time averaging on sea-air flux trends (whether real or not), rather then to make a conclusion on the reliability of the trends.

Figure 10 compares estimates of linear trends in the latent heat computed with sampling and classical meth-
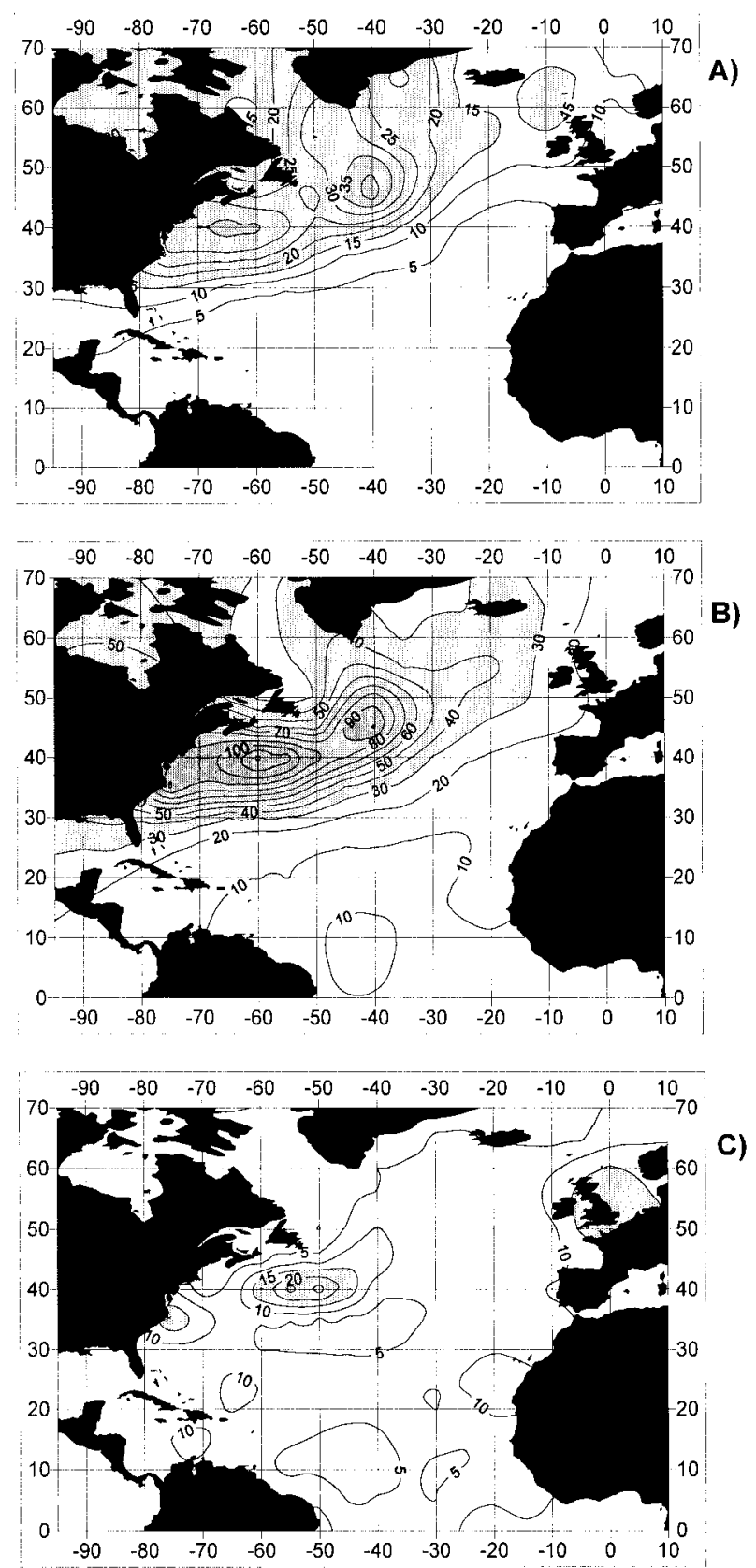

FIG. 8. Absolute sampling minus classical differences $\left(\mathrm{W} \mathrm{m}^{-2}\right)$ for $5^{\circ}$ spatial averaging for (a) sensible heat flux in January and latent heat flux in (b) January and (c) July.

ods. We give trends together with their significance as estimated from a $t$ test for the number of degrees of freedom that result from the number of independent values connected with the low-pass filter parameters (Bendat and Piersol 1966). Despite the general similarity of spatial patterns, there are some quantitative differences in the interdecadal changes of the latent heat flux computed from sampling and classical methods. The sampling estimate demonstrates significantly pos- 


\section{$A 12\left(Q_{0}\right) / A 12\left(<Q_{0}\right)$}

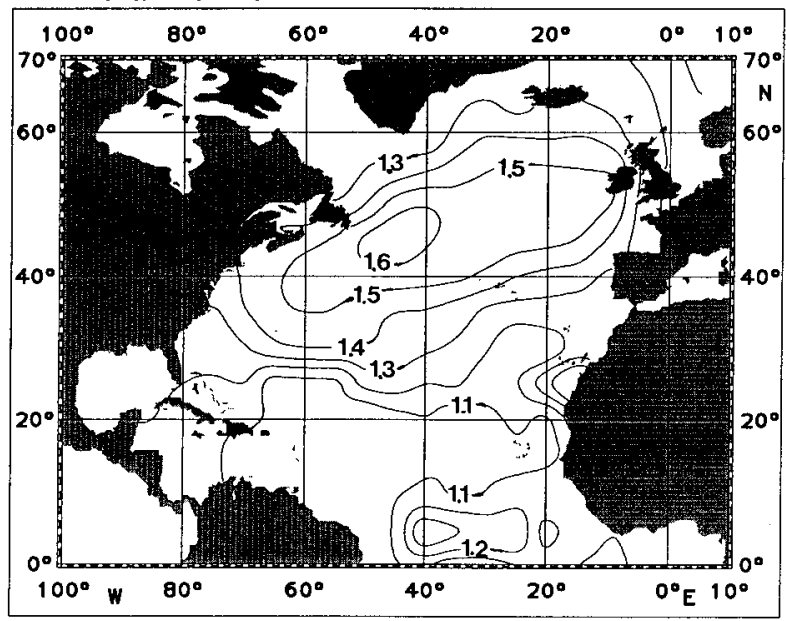

$A G\left(Q_{0}\right) / A G\left(\left\langle Q_{0}>\right)\right.$

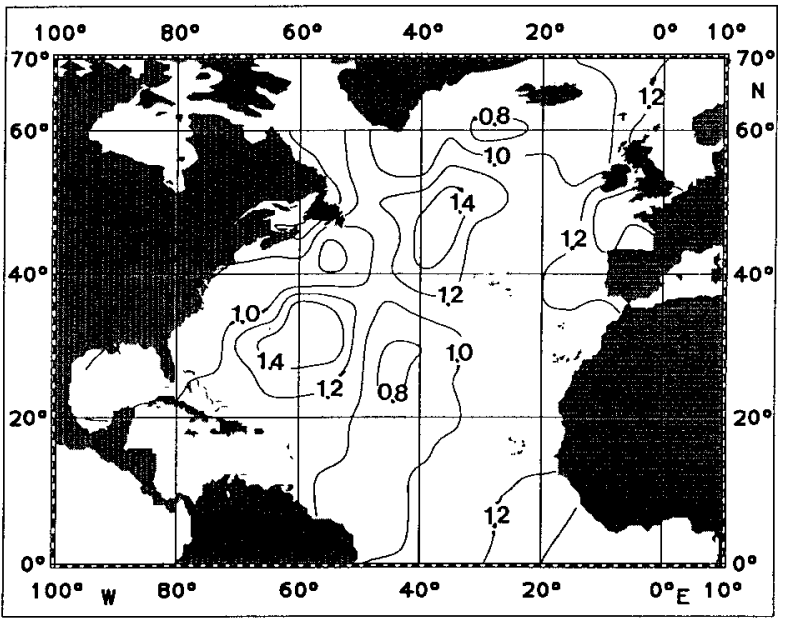

FIG. 9. Ratios between amplitudes of annual $\left(\mathrm{A}_{12}\right)$ and semiannual $\left(A_{6}\right)$ harmonics of latent heat flux, computed with sampling $\left(5^{\circ} \mathrm{av}\right.$ eraging) and classical methods

itive trends in the tropical and in the western subtropical North Atlantic. Significantly negative trends of about 3-5 $\mathrm{W} \mathrm{m}^{-2}$ per decade are observed in the central subtropical Atlantic. Negative trends in the midlatitude Atlantic are weak and are not statistically significant almost everywhere. There is a statistically significant tendency for increasing latent heat flux in the Norwegian Sea. If we consider linear trends for classical estimates of the latent heat flux (Fig. 10, bottom), there is a large area of significantly negative trends in the midlatitudes. Strongly positive trends in the Tropics become smaller and significant in only a few places. Thus, almost over the whole North Atlantic, averaging decreases positive trends and increases negative trends, reflecting the general tendency of differences between sampling and classical estimates to increase with time.

Figure 11 shows two remarkable examples of longterm changes of the anomalies of the coefficients given
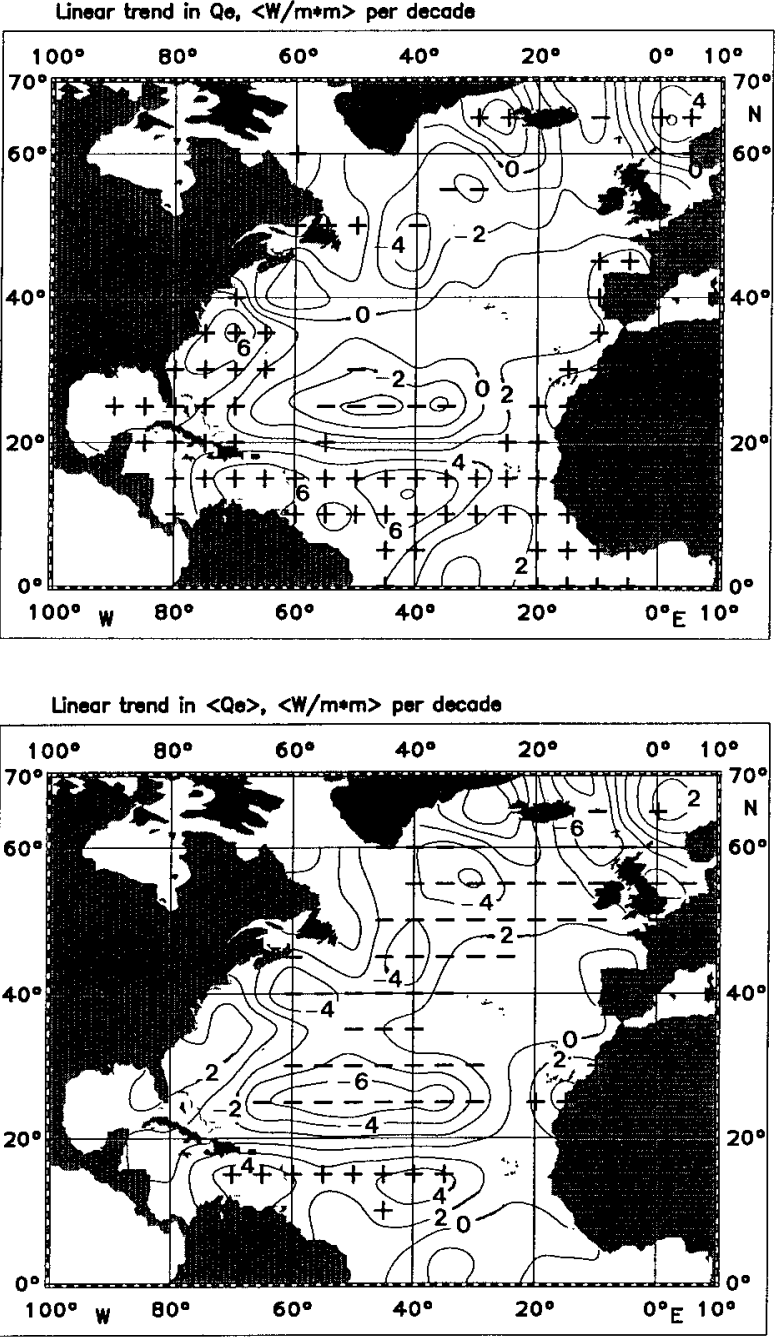

FIG. 10. Estimates of linear trends $\left(\mathrm{W} \mathrm{m}^{-2} \mathrm{decade}^{-1}\right)$ in latent heat flux, computed from sampling (top panel) and classical (bottom panel) methods for $5^{\circ}$ averaging. Pluses and minuses indicates $95 \%$ significance of the trend's estimates ( $t$ test).

by (3) for sensible and latent heat fluxes for the North Atlantic midlatitudes and subtropics. These coefficients increase from 0.03 to 0.08 decade $^{-1}$ and can have significant impact on climatic tendencies. This increase could probably be connected with changes in the statistics of storms in the North Atlantic. During the period 1950-70, there was a downward tendency in the number of midlatitudinal storms (Reitan 1974; Colucci 1976; Zishka and Smith 1980; Whittaker and Horn 1981; Lau 1988; Bell and Bosart 1989; Roebber 1989; Schinke 1993). For the late 1970s and 1980s, there are a number of reports about the increasing severity of storms in the North Atlantic (Schinke 1993), although these estimates are still questioned (von Storch et al. 1993). We will show in the discussion section below that, under certain conditions, both increase and decrease in the intensity of synoptic processes (and intramonthly variances) can 

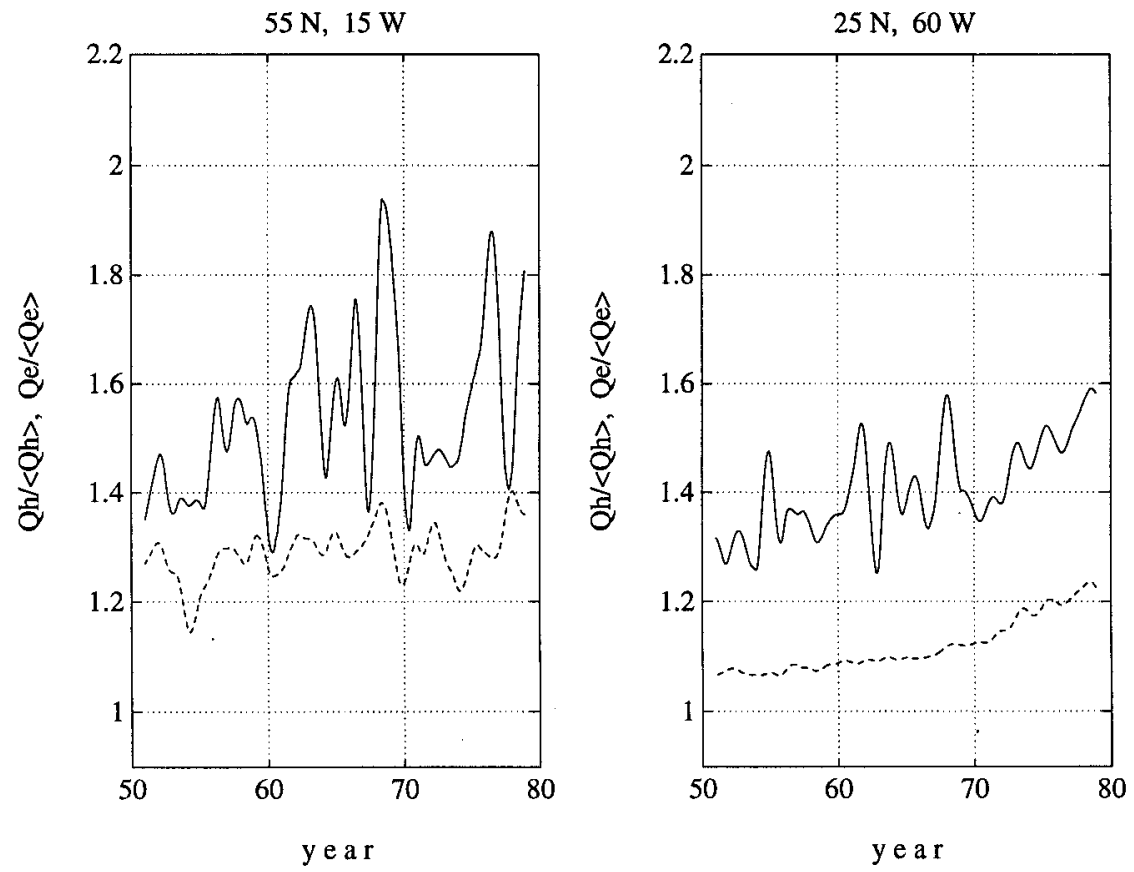

FIG. 11. Long-term changes of the anomalies of sampling-to-classical ratios computed for $5^{\circ}$ averaging for sensible heat flux (dashed line) and latent heat flux (solid line) for two locations in the North Atlantic Ocean.

increase differences between sampling and classical estimates of fluxes. Figure 11 also demonstrates significant variations of coefficients with a scale of several years. These variations may not necessarily be correlated with the variability of monthly mean fluxes. Thus, we can also expect a significant impact of intramonthly averaging (both temporal and spatial) on the short-term year-to-year variability.

\section{d. Contribution from individual covariances}

Analysis of individual correlation terms in (2) and corresponding terms for the latent heat flux is important for funding the mechanisms responsible for differences (or the absence of differences) between sampling and classical estimates. Many works referred to above found a wide range of contributions from different covariances. Most authors argue that the major contribution comes from the second and the third terms of (2). However, Josey et al. (1995) obtained at OWS L negative values of $\left\langle C_{E}^{\prime}\right\rangle\left\langle V^{\prime} \delta e^{\prime}\right\rangle$, and considered that the reason for their results showing underestimation of sampling fluxes in comparison with classical fluxes. We will present different covariances in (2) in terms of the percentage of contribution to the difference between sampling and classical estimates:

$$
P_{n}=\operatorname{Cov}_{n} /\left(\left\langle C_{T} V \delta T\right\rangle-\left\langle C_{T}\right\rangle\langle V\rangle\langle\delta T\rangle\right),
$$

where $P_{n}$ is the percentage of contribution of the covariance $\operatorname{Cov}_{n}$ and $n$ corresponds to the numbers given under the formula (2). We will present the analysis for $5^{\circ}$ spatial averaging, which in general agrees well with calculations done for $2^{\circ}$ averaging. Figure 12 shows the percentages of contributions from covariances $2-5$ for sensible heat flux; in Fig. 13, corresponding contributions are given for latent heat flux. Term 2 indicates the highest relative values in the mid- and high latitudes and appears to be almost responsible for the midlatitudinal maximum of $\xi_{H}$ (Fig. 3). In the Tropics and subtropics this term decreases sharply and indicates negative values in the central tropical Atlantic. The covariance $\left\langle C_{T}^{\prime} \delta T^{\prime}\right\rangle\langle V\rangle$ gives the major contribution in the low latitudes, where it compensates the negative contribution from other terms. Term 4 has the largest effect in high latitudes, and decreases to negative values in the Tropics. The role of $\left\langle C_{T}^{\prime} V^{\prime} \delta T^{\prime}\right\rangle$ is smaller in comparison with terms $2-4$ and is characterized by weakly negative values in the Tropics and subtropics and by a $10 \%$ to $20 \%$ contribution in middle and high latitudes. Thus, the main contribution in the midlatitudes comes from the second term of (2). In high latitudes, the second term still contributes a great deal, but the contribution from the other terms is also significant and ranges from $10 \%$ to $30 \%$. In the tropical west and central Atlantic, the term $\left\langle C_{T}^{\prime} \delta T^{\prime}\right\rangle\langle V\rangle$ overcompensates the small negative contribution from the other terms.

For latent heat flux (Fig. 13), the term $\left\langle C_{E}^{\prime}\right\rangle\left\langle V^{\prime} \delta e^{\prime}\right\rangle$ gives a positive contribution of $20 \%$ to $60 \%$ in the west Atlantic middle and high latitudes and in the tropical and subtropical east Atlantic. In the central Atlantic and in the midlatitudinal east Atlantic, the second term is weakly but constantly negative. The contribution from $\left\langle C_{E}^{\prime} \delta e^{\prime}\right\rangle\langle V\rangle$ is very similar to that for $\left\langle C_{T}^{\prime} \delta T^{\prime}\right\rangle\langle V\rangle$. This 

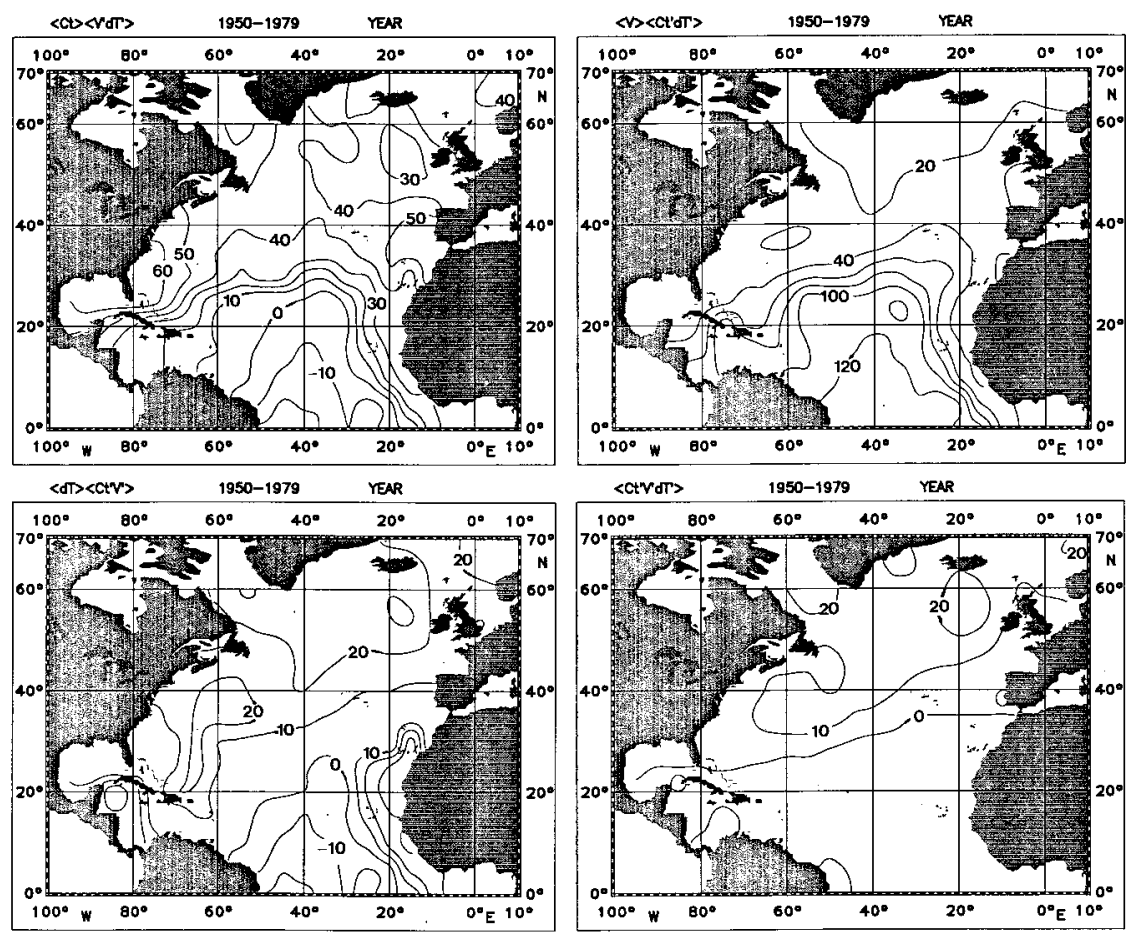

FIG. 12. Percentages of contribution from different covariances from (2) into difference between sampling and classical estimates of sensible heat flux for $5^{\circ}$ averaging.
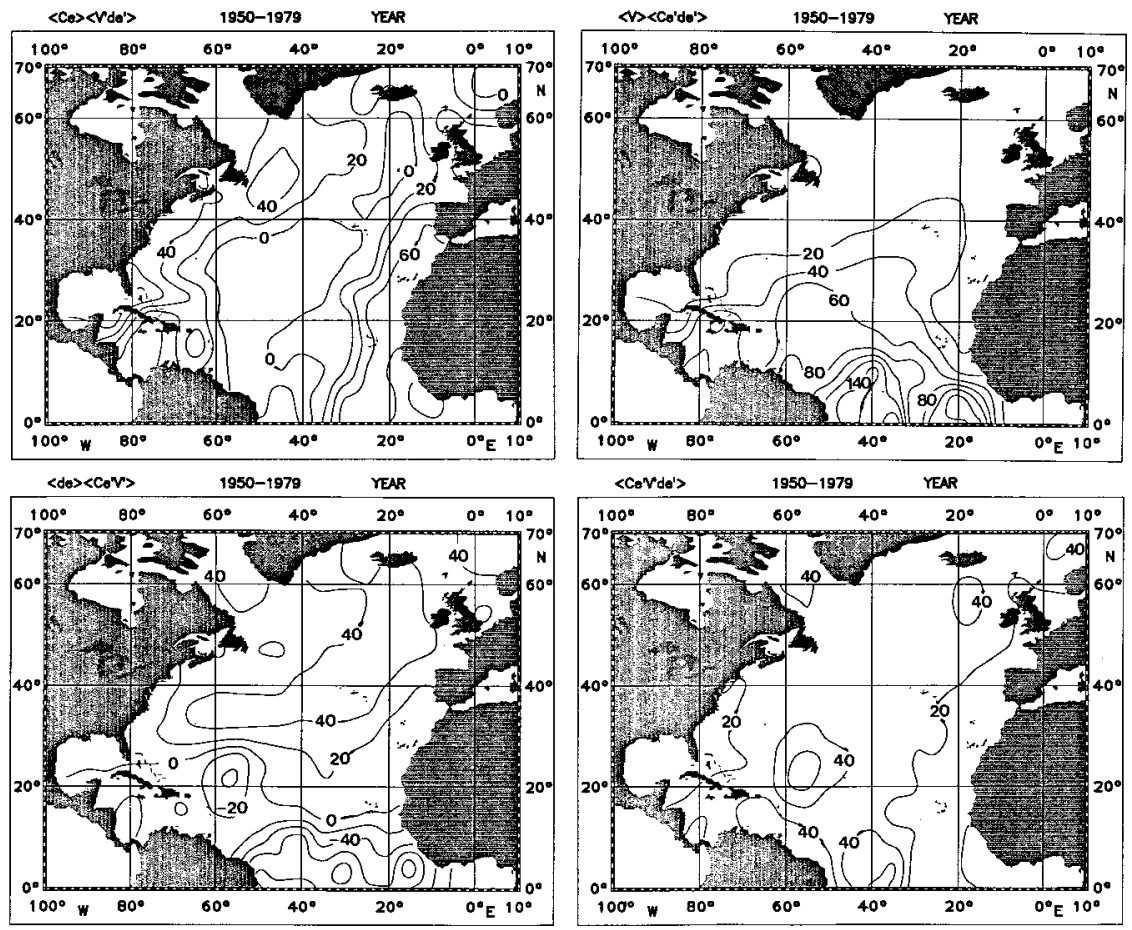

FIG. 13. As in Fig. 12 but for latent heat flux. 
TABLE 2. Seasonal estimates of the percentage of contribution from different covariances in (2) for three locations in the North Atlantic. Upper number in each pair is for sensible heat flux, and lower one is for latent heat.

\begin{tabular}{|c|c|c|c|c|}
\hline \multirow[b]{2}{*}{ Month } & \multicolumn{4}{|c|}{ Covariance } \\
\hline & 2 & 3 & 4 & 55 \\
\hline \multicolumn{5}{|c|}{ West Atlantic midlatitudes, $45^{\circ} \mathrm{N}, 45^{\circ} \mathrm{W}$} \\
\hline Jan & $\begin{array}{l}42 \\
41\end{array}$ & $\begin{array}{r}15 \\
6\end{array}$ & $\begin{array}{l}24 \\
24\end{array}$ & $\begin{array}{l}19 \\
29\end{array}$ \\
\hline Apr & $\begin{array}{l}51 \\
53\end{array}$ & $\begin{array}{l}27 \\
10\end{array}$ & $\begin{array}{l}14 \\
16\end{array}$ & $\begin{array}{r}8 \\
21\end{array}$ \\
\hline Jul & $\begin{array}{r}6 \\
-8\end{array}$ & $\begin{array}{r}103 \\
51\end{array}$ & $\begin{array}{r}4 \\
13\end{array}$ & $\begin{array}{r}-13 \\
44\end{array}$ \\
\hline Oct & $\begin{array}{l}55 \\
53\end{array}$ & $\begin{array}{r}23 \\
9\end{array}$ & $\begin{array}{l}14 \\
20\end{array}$ & $\begin{array}{r}8 \\
15\end{array}$ \\
\hline \multicolumn{5}{|c|}{ Northeast Atlantic, $50^{\circ} \mathrm{N}, 20^{\circ} \mathrm{W}$} \\
\hline Jan & $\begin{array}{r}17 \\
-12\end{array}$ & $\begin{array}{l}33 \\
14\end{array}$ & $\begin{array}{l}30 \\
59\end{array}$ & $\begin{array}{l}20 \\
39\end{array}$ \\
\hline Apr & $\begin{array}{l}54 \\
39\end{array}$ & $\begin{array}{l}38 \\
17\end{array}$ & $\begin{array}{r}6 \\
32\end{array}$ & $\begin{array}{r}2 \\
12\end{array}$ \\
\hline Jul & $\begin{array}{r}-3 \\
-181\end{array}$ & $\begin{array}{r}118 \\
29\end{array}$ & $\begin{array}{r}-2 \\
21\end{array}$ & $\begin{array}{r}-13 \\
31\end{array}$ \\
\hline Oct & $\begin{array}{r}40 \\
-6\end{array}$ & $\begin{array}{l}36 \\
20\end{array}$ & $\begin{array}{l}17 \\
57\end{array}$ & $\begin{array}{r}7 \\
29\end{array}$ \\
\hline \multicolumn{5}{|c|}{ Central tropical Atlantic, $20^{\circ} \mathrm{N}, 40^{\circ} \mathrm{W}$} \\
\hline Jan & $\begin{array}{l}41 \\
42\end{array}$ & $\begin{array}{l}62 \\
23\end{array}$ & $\begin{array}{r}2 \\
16\end{array}$ & $\begin{array}{r}-5 \\
19\end{array}$ \\
\hline Apr & $\begin{array}{r}-3 \\
2\end{array}$ & $\begin{array}{r}115 \\
47\end{array}$ & $\begin{array}{r}3 \\
33\end{array}$ & $\begin{array}{r}-15 \\
18\end{array}$ \\
\hline Jul & $\begin{array}{r}-22 \\
-8\end{array}$ & $\begin{array}{r}148 \\
69\end{array}$ & $\begin{array}{r}-20 \\
8\end{array}$ & $\begin{array}{r}-6 \\
31\end{array}$ \\
\hline Oct & $\begin{array}{l}-24 \\
-26\end{array}$ & $\begin{array}{l}150 \\
137\end{array}$ & $\begin{array}{l}-17 \\
-14\end{array}$ & $\begin{array}{r}-9 \\
3\end{array}$ \\
\hline
\end{tabular}

term determines completely the sampling-to-classical differences in the tropical west and central Atlantic. Term 4 for the latent heat flux, in comparison with sensible heat flux, indicates higher positive and negative contributions in the midlatitudes and in the Tropics, respectively. The triple covariance $\left\langle C_{E}^{\prime} V^{\prime} \delta e^{\prime}\right\rangle$ has local maxima in the Tropics and in the northeast Atlantic, where it contributes from $40 \%$ to $60 \%$ of $\left\langle C_{T} V \delta T\right\rangle-$ $\left\langle C_{T}\right\rangle\langle V\rangle\langle\delta T\rangle$.

Table 2 shows seasonal estimates of the contributions from different covariances for three locations in the North Atlantic Ocean. For the Newfoundland Basin, covariances 2 and 3 indicate pronounced seasonal dependence, with the highest values in winter and in summer, respectively. The terms $\left\langle C_{T}^{\prime}\right\rangle\left\langle V^{\prime} \delta T^{\prime}\right\rangle$ and $\left\langle C_{E}^{\prime}\right\rangle\left\langle V^{\prime} \delta e^{\prime}\right\rangle$ give the major contribution during the cold season. In summer, the whole contribution comes from the third term in (2). There is a general similarity in the behavior of covariances for sensible and latent heat fluxes. Remarkable differences are obtained only for covariances $\left\langle C_{T}^{\prime} V^{\prime} \delta T^{\prime}\right\rangle$ and $\left\langle C_{E}^{\prime} V^{\prime} \delta e^{\prime}\right\rangle$ in summer. If we consider the northeast Atlantic, the most significant impact for sensible heat flux will be from the third term and, for latent heat, it will be from the fourth. Remarkably, the co- variance $\left\langle C_{E}^{\prime}\right\rangle\left\langle V^{\prime} \delta e^{\prime}\right\rangle$ is significantly negative during almost the whole year. This is in agreement with the recent results of Josey et al. (1995), who found negative sampling-to-classical differences for the latent heat flux on the basis of OWS L data. In the central tropical Atlantic, the covariance $\left\langle C_{T}^{\prime} \delta T^{\prime}\right\rangle\langle V\rangle$ is largely responsible for sampling-to-classical differences and overcompensates the contribution from other terms in (2) for nearly all seasons. A significant contribution from the term 2 is obtained in winter only for both sensible and latent fluxes.

If we compare our estimates of different correlation terms with other results (Kondo 1972; Esbensen and Reynolds 1981; Hanawa and Toba 1987; Gulev 1994; Josey et al. 1995), there will be general agreement for covariances $\left\langle C_{T}^{\prime}\right\rangle\left\langle V^{\prime} \delta T^{\prime}\right\rangle$ and $\left\langle C_{T}^{\prime} \delta T^{\prime}\right\rangle\langle V\rangle$ for sensible heat flux and for the corresponding covariances for latent heat flux. For the other two covariances, different authors give very different estimates. For example, Staneva et al. (1995), on the basis of the National Centers for Environmental Prediction reanalysis, found the covariance $\left\langle C_{T}^{\prime} V^{\prime}\right\rangle\langle\delta T\rangle$ to be homogeneously negative and the term $\left\langle C_{T}^{\prime} V^{\prime} \delta T^{\prime}\right\rangle$ to be weakly, but homogeneously, positive in the Black Sea. At the same time, Hanawa and Toba (1987) give negative values for these terms for both sensible and latent fluxes. Simmonds and Dix (1989), in their model study, obtained almost entirely positive covariance $\left\langle C_{T}^{\prime} V^{\prime}\right\rangle\langle\delta T\rangle$, and primarily negative terms $\left\langle C_{T}^{\prime} V^{\prime} \delta T^{\prime}\right\rangle$ and $\left\langle C_{E}^{\prime} V^{\prime} \delta e^{\prime}\right\rangle$. In the discussion section below, we will return to this problem and give possible reasons for the disagreements.

\section{e. Relationships of sampling-to-classical ratios with mean parameters, number of samples, and intrabox network type}

The dependencies of coefficients (3) on mean parameters can provide the possibility of parameterizing the effects of averaging. Considering the dependency of the coefficients in (3) on mean monthly wind speed and stability for the whole North Atlantic, we obtained too much scatter to discuss any relationships with confidence. At the same time, in the northwest Atlantic (restricted by $30^{\circ} \mathrm{N}, 55^{\circ} \mathrm{N}$, and $30^{\circ} \mathrm{W}$ ) in the cold season (from October to March), there is a clear dependence of sampling-to-classical ratios for latent heat flux on monthly mean wind speed and stability. Figure 14 shows the behavior of the $\xi_{E}^{5}$ coefficient with wind speed and humidity gradient in this limited area. There were no such clear relationships for sensible heat flux. The sampling-to-classical ratio for latent heat flux decreases with increasing $\delta \mathrm{e}$ and increases with wind speed, in agreement with results of Gulev (1994) for temporal averaging. The relationship obtained, the same manner as in Gulev (1994), is the following:

$$
\xi_{E}^{5}(\delta e, V)=1.07+0.041 V+1.12 e^{-0.33 \delta e},
$$

where $\delta e$ and $V$ are the monthly mean humidity gradient and wind speed, averaged over a $5^{\circ}$ box. For other sea- 

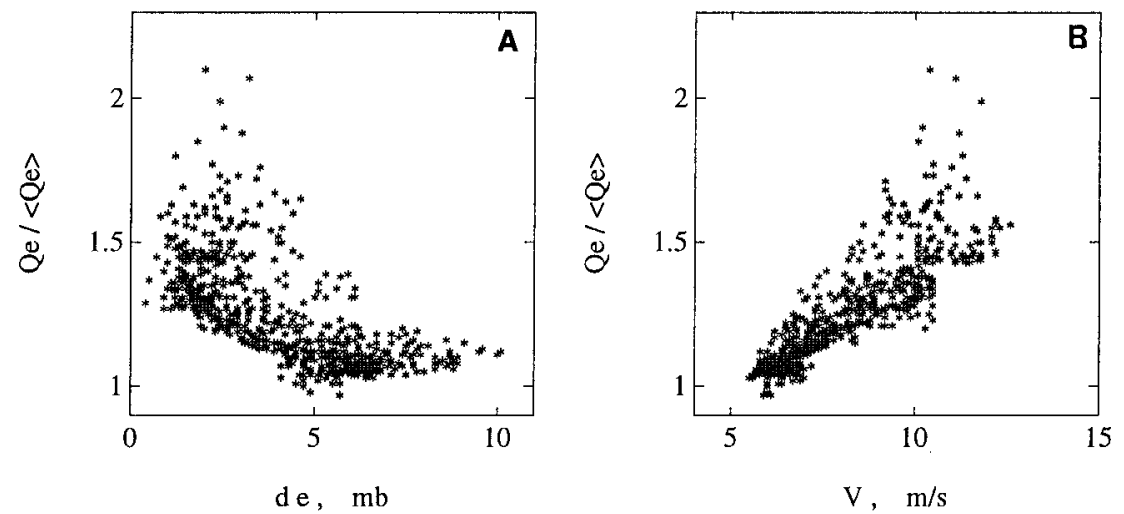

FIG. 14. Dependence of sampling-to-classical ratios ( $5^{\circ}$ averaging) for latent heat flux on (a) the humidity difference and (b) the wind speed.

sons and other areas of the North Atlantic, there are no clear relationships. In the Tropics, both coefficients (3) and wind speed are much more homogeneous than in the midlatitudes. Moreover, taking into account the considerably smaller number of observations in the Tropics, we expect a dependence of the coefficients on the completeness of sampling rather than on mean wind speed and stability.

To study the possible influence of undersampling on the coefficients' values, we first selected several $5^{\circ}$ squares in the midlatitudes and subtropics, which have a very large number of observations. Then we randomly selected certain numbers of samples (from 10 to 1500 month $^{-1}$ ) and computed the coefficients in (3). When the number of observations was higher than 100 month ${ }^{-1}$, there were no relationships between the number of samples and sampling-to-classical ratios. At the same time, in the case of extreme undersampling, the coefficients given by (3) increase with the number of observations. The tendency ranges from 0.01 to 0.06 per 20 samples. We then selected several Marsden squares with a very wide range in the number of observations during $1950-79$, possibly reflecting historical changes in the main ship routes. Figure 15 shows the relationship of sampling-to-classical ratios, with the number of samples for Marsden box 78 (bounded by $30^{\circ} \mathrm{N}, 20^{\circ} \mathrm{N}, 60^{\circ} \mathrm{W}$, and $50^{\circ} \mathrm{W}$ ), which provides a wide range of the number of samples per month. Diagrams in Fig. 15 are given for all four $5^{\circ}$ boxes for this Marsden square, and thus, the number of samples should be approximately divided by 4 . The highest correlation is obtained for latent heat flux. Thus the number of observations influence the differences between sampling and classical estimates of fluxes when there are less than 100 samples per month in a $5^{\circ}$ box. That, in particular, was the reason to reject the possibility of using COADS release 1a data, which have considerable undersampling in many areas (Fig. 1). At the same time, we note here that for the period 1950-80, in general the number of observations greatly exceeds 100 everywhere, except in the central tropical and equatorial Atlantic.

The intrabox network type can also have significant effects on estimates of sampling-to-classical ratios. Following Morrissey and Maliekal (1995), we examined four intrabox networks: a linear network aligned along the major axis of the spatial correlation function of basic
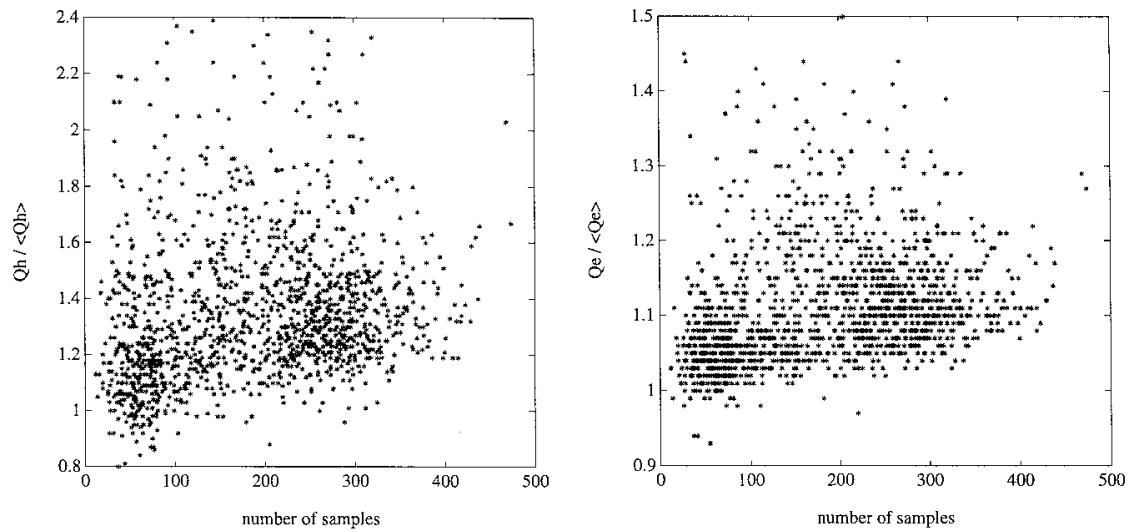

FIG. 15. Dependence of sampling-to-classical ratios for (a) sensible heat flux and (b) latent heat flux on the number of samples for Marsden box 78 . 
TABLE 3. Sampling-to-classical ratios for different intrabox network types in the northwest Atlantic. Estimates are averaged over six $5^{\circ}$ boxes.

\begin{tabular}{ccccc}
\hline \hline $\begin{array}{c}\text { Sam- } \\
\text { pling- } \\
\text { to-clas- } \\
\text { sical } \\
\text { ratios }\end{array}$ & L1 & L2 & RN & CN \\
\hline$\xi_{\mathrm{H}}$ & 1.54 & 1.79 & 1.56 & 1.50 \\
$\xi_{\mathrm{E}}$ & 1.32 & 1.16 & 1.30 & 1.27 \\
\hline
\end{tabular}

parameters at the sea-air interface (L1), a linear network aligned across this axis (L2), a random network (RN), and a clustered network $(\mathrm{CN})$. Again, we studied several midlatitudinal $5^{\circ}$ boxes in order to model all these networks and to obtain a sufficient number of samples at the same time. These boxes included OWSs, which can be considered to be an example of a clustered network. Results are presented in Table 3. There is not much difference between at least three of the networks. The spatial correlation of synoptic processes along the North Atlantic storm track is very high, and estimates based on the random network are very close to those obtained from the L1 network or from the clustered network. This is in agreement with the small differences between $5^{\circ}$ and $2^{\circ}$ averaging shown above (section $4 a, b$ ). Significant departures are obtained only for the L2 network, which underestimates the sampling-to-classical ratios for latent heat flux and indicates an overestimation of the ratio for sensible heat flux. But in practice, purely linear or clustered networks are hardly detectable in COADS data. Even for tropical boxes with lower numbers of observations, we always deal with primarily linear networks, where many additional observations are randomly located out of linear track. Ship routes never coincide entirely, but are close to each other. So, in practice, linear networks are represented by relatively wide tracks rather than a single narrow line. We can conclude that the network type does not have significant effects on sampling-to-classical differences.

\section{Discussion}

The results can be discussed from a number of viewpoints. Pronounced differences between sampling and classical estimates of sensible heat flux appear in middle and high latitudes in the cold season, as latent heat flux differences are significant over nearly the whole North Atlantic for all seasons. Pronounced seasonal and interannual variability of the sampling-to-classical ratios indicate that not only the climatological means, but also the variability, could be very different when estimated with sampling and classical methods. Spatial averaging has a larger effect in the Tropics and subtropics; in midlatitudes, the major contribution comes from the temporal averaging. We found that differences between sampling and classical estimates could be sensitive to the number of samples.
We have mentioned the possible influence of the choice of the transfer coefficients scheme on the sampling minus classical differences. To show the possible influence of different schemes on the estimates of sampling minus classical differences, we used for the comparison the parameterizations of Smith (1988) and Liu et al. (1979), which indicate, respectively, slightly negative and strongly negative correlations between transfer coefficients and wind speed in contrast to Ariel et al. (1981)'s scheme. Figure 16 shows sampling-to-classical ratios for sensible and latent heat fluxes, computed for $5^{\circ}$ averaging with the use of these two parameterizations. If we compare these results with Fig. 3 based on the Ariel et al. (1981) parameterization, there is a general similarity in spatial patterns, although the $\xi_{H}$ and $\xi_{E}$ coefficients are $10 \%$ to $30 \%$ smaller than those presented in Fig. 3. The largest differences between schemes occur in the midlatitudes. In the western subtropics, both the Liu et al. (1979) and Smith (1988) parameterizations (Fig. 16) indicate areas where sampling-to-classical ratios are slightly smaller than 1 and vary from 0.97 to 1.00. Smith's (1988) parameterization gives $2 \%$ to $6 \%$ higher $\xi_{H}$ and $\xi_{E}$ coefficients in comparison with the Liu et al. (1979) scheme. Figure 17 displays absolute winter sampling minus classical differences, computed with the Liu et al. (1979) and Smith (1988) parameterizations in the same manner as in Fig. 8 for the Ariel et al. (1981) method. The maximum of winter departure of sampling estimate from classical estimate for sensible heat flux is observed west of Newfoundland and ranges from 20 to $30 \mathrm{~W} \mathrm{~m}^{-2}$. In the Tropics and the east midlatitudes, absolute errors of sensible heat flux are rather small to be considered with confidence. For the latent heat flux, the midlatitudinal maximum of sampling minus classical differences ranges from 40 to $65 \mathrm{~W} \mathrm{~m}^{-2}$ for Liu et al. (1979) and from 50 to $70 \mathrm{~W} \mathrm{~m}^{-2}$ for Smith (1988), $40 \%$ to $50 \%$ percent smaller than the absolute errors obtained with the Ariel et al. (1988) parameterization. Note here that the Liu et al. (1979) and Smith (1988) schemes give 3\% to $15 \%$ smaller fluxes (be they sampling or classical estimates) in comparison with the Ariel et al. (1981) scheme.

Possible reasons for the differences in the estimates of the averaging effects can be discussed in terms of the contributions from different covariances in (2). Term 2 in (2) results from the correlation between wind speed and sea-air temperature (or humidity for latent heat) and is connected with synoptic and mesoscale processes at the sea-air interface. In the northwest Atlantic midlatitudes, we should expect mostly positive and large contributions from this term. Cold polar air in the cold sectors of midlatitudinal cyclones and polar lows provides high correlations of temperature and humidity gradients with wind speed, especially in the vicinity of SST fronts and the North American coast. Remarkably, Esbensen and Reynolds (1981), who got in general small differences between sampling and classical estimates, obtained positive values of $\left\langle C_{T}^{\prime}\right\rangle\left\langle V^{\prime} \delta T^{\prime}\right\rangle$ at OWS D for 

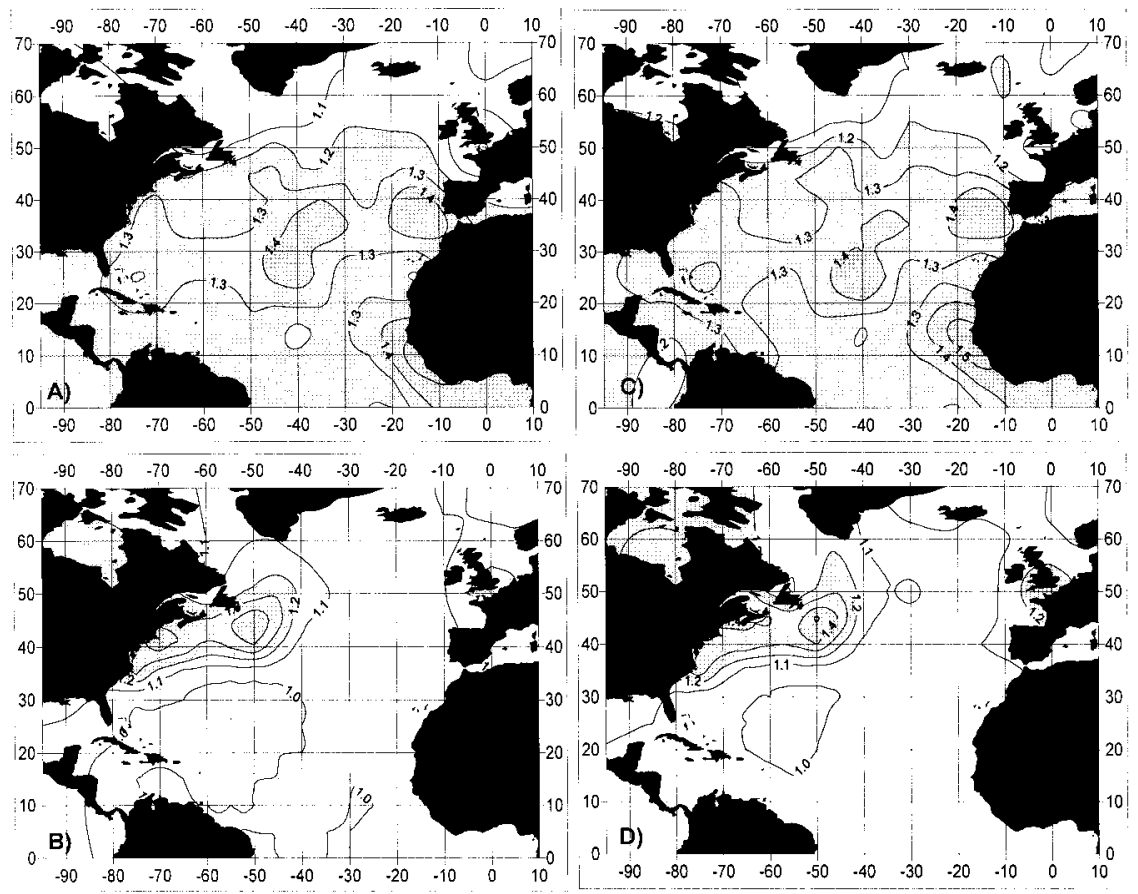

FIG. 16. Climatological maps of sampling-to-classical ratios for $5^{\circ}$ spatial averaging for (a) and (c) sensible heat flux and (b) and (d) latent heat flux, computed with the (a) and (b) Liu et al. (1979) and (c) and (d) Smith (1988) parameterizations.
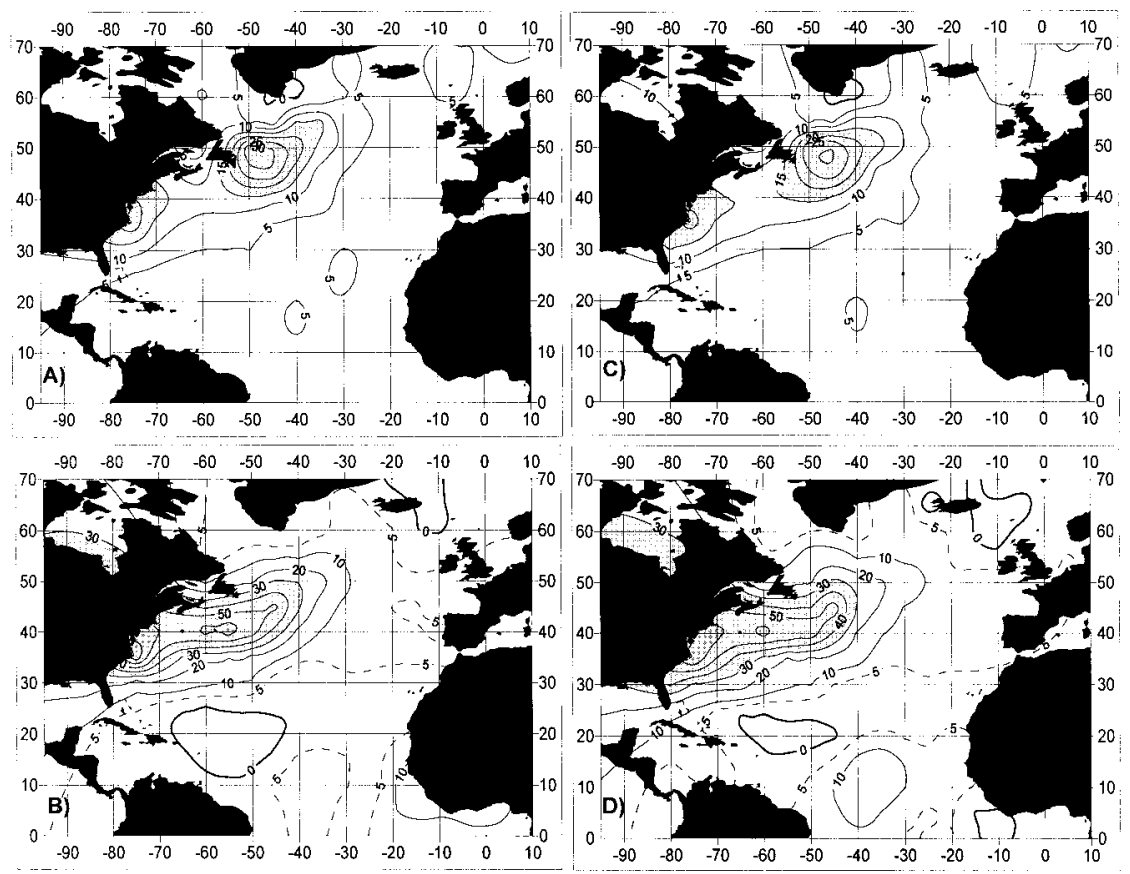

FIG. 17. Absolute January sampling minus classical differences $\left(\mathrm{W} \mathrm{m}^{-2}\right)$ for $5^{\circ}$ spatial averaging (a) and (c) for sensible heat flux and (b) and (d) latent heat flux, computed with the (a) and (b) Liu et al. (1979) and (c) and (d) Smith (1988) parameterizations. 
winter. Alternatively, in the northeast Atlantic midlatitudes, cyclones are well developed, SST fronts are not sharp (if they exist), and strong winds are mostly observed in the warm sectors of cyclones. In this case, the increase of wind has the effect of decreasing sea-air contracts. Thus, we expect primarily negative covariances $\left\langle V^{\prime} \delta T^{\prime}\right\rangle$ and $\left\langle V^{\prime} \delta e^{\prime}\right\rangle$ in the northeast Atlantic. This is in agreement with recent results of Josey et al. (1995), which indicate negative contributions from these covariances at OWS L. In the subtropics, these terms could be variable, although in the Tropics and the central Atlantic, we can expect that the contribution will be negative. Increasing wind contributes here to the mixing of the upper ocean layer and can decrease SST if the mixing is effective enough. This covariance does not depend much on the choice of parameterization and could be predicted from synoptic and mesoscale statistics of individual variables. COADS MSTGs include direct estimates of covariances $\left\langle V^{\prime} \delta T^{\prime}\right\rangle$ and $\left\langle V^{\prime} \delta e^{\prime}\right\rangle$ to provide users with the possibility of estimating quasi-sampling fluxes from monthly averaged data. Particularly, Cayan (1992a,b,c) used in his study these derived variables. If one uses these products, he or she will account partially for sampling-to-classical differences, but taking into consideration the remarkable spatial and temporal inhomogeneity of the contribution from other covariances, the obtained fluxes probably will also be inhomogeneously corrected. At the same time, for the northwest Atlantic midlatitudes, the use of these derived products can account at least for $30 \%$ to $60 \%$ of sampling minus classical differences.

Covariances $\left\langle C_{T}^{\prime} \delta T^{\prime}\right\rangle\langle V\rangle$ and $\left\langle C_{T}^{\prime} V^{\prime}\right\rangle\langle\delta T\rangle$ and the corresponding terms for latent heat flux are largely determined by the parameterizations of the transfer coefficients. All known parameterizations indicate growing $C_{T}$ and $C_{E}$ with sea-air temperature and humidity differences. Thus, a positive contribution from the covariance 3 is predicted, and different schemes will only change the magnitude of their contribution. Usually authors use the Businger-Dyer flux-gradient relations (Dyer 1974) and the results of the profiles integration from Paulson (1970) to evaluate coefficients, and results do not depart significantly from each other. All parameterizations also indicate a much higher dependence of coefficients on stability for low and moderate winds than for strong winds. For wind speeds higher than 15 $\mathrm{m} \mathrm{s}^{-1}$, the variability of transfer coefficients with seaair temperature and humidity gradients ranges from several tenths of a percent to several percent. For winds lower than $10 \mathrm{~m} \mathrm{~s}^{-1}$, the range is several times larger; thus, not surprisingly, covariances $\left\langle C_{T}^{\prime} \delta T^{\prime}\right\rangle\langle V\rangle$ and $\left\langle C_{E}^{\prime} \delta e^{\prime}\right\rangle\langle V\rangle$ give their most significant contributions in Tropics, where winds are small. The most variable estimates are obtained for covariances $\left\langle C_{T}^{\prime} V^{\prime}\right\rangle\langle\delta T\rangle$ and $\left\langle C_{E}^{\prime} V^{\prime}\right\rangle\langle\delta e\rangle$. These terms result from the dependence of transfer coefficients on the wind speed; this dependence is different from scheme to scheme. A number of schemes indicate an increase of transfer coefficients
TABLE 4. Seasonal estimates of the percentages of contribution from different covariances in (2), computed from the Smith (1988) (S) and Liu et al. (1981) (L) schemes, for the northwest Atlantic midlatitudes $\left(45^{\circ} \mathrm{N}, 45^{\circ} \mathrm{W}\right)$. Upper number in each pair is for sensible heat flux, and lower one is for the latent heat.

\begin{tabular}{|c|c|c|c|c|c|c|c|c|}
\hline \multirow[t]{3}{*}{ Month } & \multicolumn{8}{|c|}{ Covariance } \\
\hline & \multicolumn{2}{|c|}{2} & \multicolumn{2}{|c|}{3} & \multicolumn{2}{|c|}{4} & \multicolumn{2}{|c|}{5} \\
\hline & $\mathrm{S}$ & $\mathrm{L}$ & $\mathrm{S}$ & $\mathrm{L}$ & $\mathrm{S}$ & $\mathrm{L}$ & $\mathrm{S}$ & $\mathrm{L}$ \\
\hline \multicolumn{9}{|c|}{ West Atlantic midlatitudes, $45^{\circ} \mathrm{N}, 45^{\circ} \mathrm{W}$} \\
\hline Jan & 69 & 72 & 40 & 39 & -6 & -9 & -3 & -2 \\
\hline & 77 & 81 & 34 & 32 & -8 & -12 & -3 & -1 \\
\hline \multirow[t]{2}{*}{ Jul } & 53 & 61 & 49 & 41 & -3 & 2 & 1 & -4 \\
\hline & 67 & 70 & 39 & 37 & -5 & -4 & 1 & -3 \\
\hline
\end{tabular}

with wind speed at least for moderate and strong winds (Bunker 1976; Ariel et al. 1981; Isemer and Hasse 1987). Liu et al. (1979) gives an example of the negative correlation between coefficients values and wind speed. The parameterizations of Large and Pond (1982) and Smith (1988) suggest that coefficients are constant for strong winds and give a slightly negative correlation for moderate winds in unstable conditions. Josey et al. (1995) used Smith's (1988) parameterization and found the covariance $\left\langle C_{E}^{\prime} V^{\prime}\right\rangle\langle\delta e\rangle$ to be weakly negative for both the summer and winter at OWS L. For small winds $(<6$ $\mathrm{m} \mathrm{s}^{-1}$ ), practically all parameterizations give the decrease of coefficients with growing wind. Thus, we can expect a primarily negative contribution from this term in low latitudes regardless of the choice of scheme, and very different estimates in the mid- and high latitudes depending on the scheme used. The triple covariance $\left\langle C_{T}^{\prime} V^{\prime} \delta T^{\prime}\right\rangle$ and the corresponding term for latent heat flux are the most complicated to analyze. For strong winds, it should be definitely positive for parameterizations with increasing coefficients with wind speed and definitely negative for those that indicate the opposite tendency. Josey et al. (1995) argue that this term is usually negligibly small. We found it to be significantly positive in the Tropics for latent heat flux, resulting from our use of the Ariel et al. (1981) method, which indicates a high correlation between $C_{E}$ and $\delta e$ for moderate and small winds.

Table 4 shows estimates of individual correlation terms in (2), where the parameterizations of Smith (1988) and Liu et al. (1981) are used. These results can be compared with our estimates (Table 2). For the North Atlantic midlatitudes, the largely negative contributions of terms 4 and 5 for the Liu et al. (1979) and Smith (1988) parameterizations are compensated by positive terms 2 and 3. Negative contributions of $\left\langle C_{T}^{\prime} V^{\prime}\right\rangle\langle\delta T\rangle$ and $\left\langle C_{E}^{\prime} V^{\prime}\right\rangle\langle\delta e\rangle$ lead here to $20 \%$ to $30 \%$ smaller absolute differences between sampling and classical methods with these two parameterizations than in Ariel et al. (1981), which we used. An impact of different schemes of the estimates of sampling minus classical differences is seen from the computation of the Ledvina et al. (1993) term. Figure 18 shows estimates of this term for the 


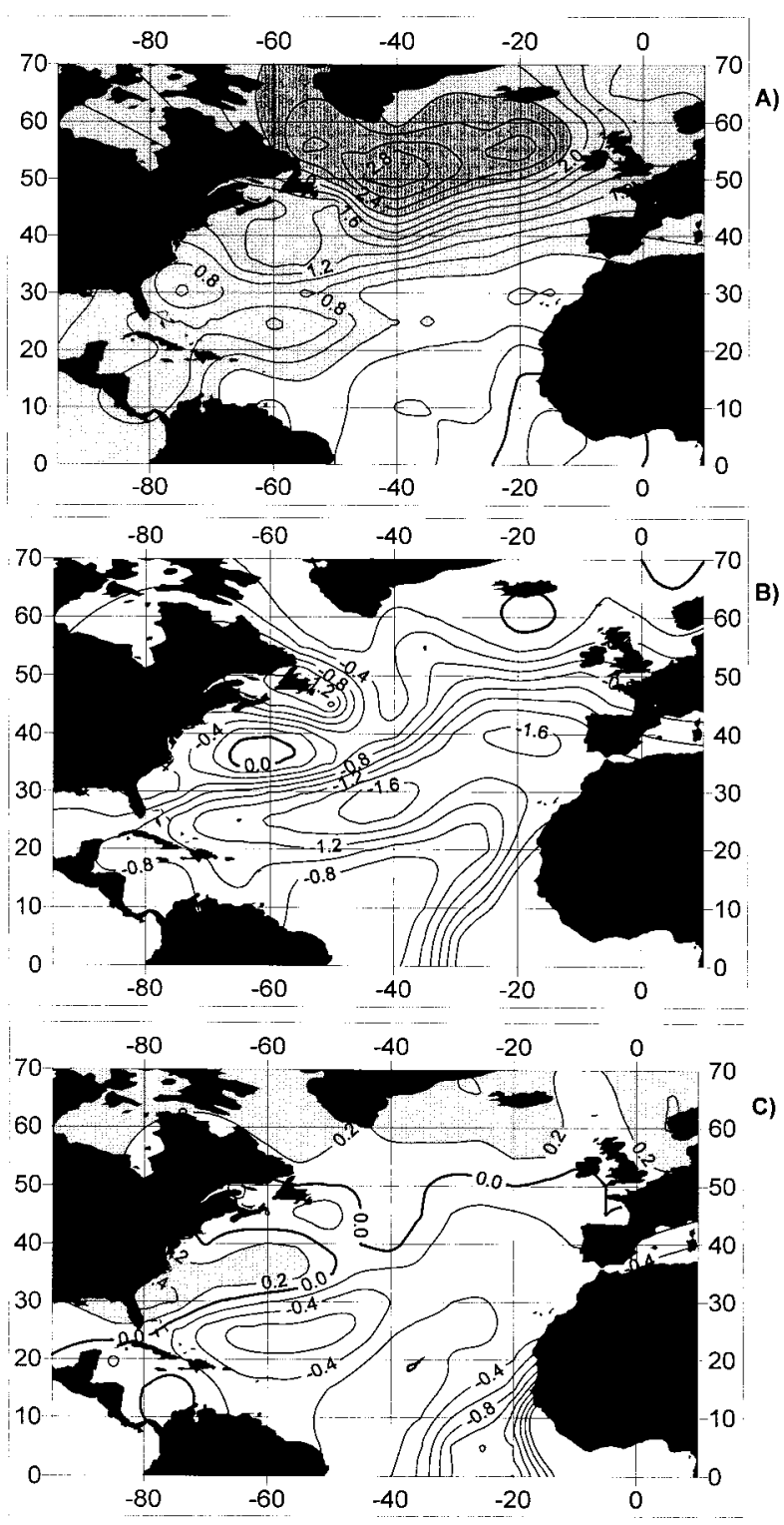

FIG. 18. Estimates of the percentages of contribution of the Ledvina et al. (1993) term for the (a) Ariel et al. (1981), (b) Liu et al. (1979), and (c) Smith (1988) parameterizations, computed for $5^{\circ}$ averaging.

latent heat flux, expressed as the percentage contribution to the sampling estimate of flux:

$$
P\left(Q_{E}\right)_{\text {led }}=\left\langle\left(\tilde{C}_{E}-\bar{C}_{E}\right) V \delta e\right\rangle /\left\langle\tilde{C}_{E} V \delta e\right\rangle,
$$

where $\bar{C}_{E}$ is the transfer coefficient computed from average conditions and $\tilde{C}_{E}$ is the space-time-averaged coefficient. The contribution of the Ledvina et al. (1993) term varies from $-2 \%$ to $+3 \%$. For parameterizations with a positive correlation of the coefficient with wind speed (Bunker 1976; Ariel et al. 1981; Isemer and Hasse 1987) (Fig. 18a), its contribution is primarily positive, with a maximum of $2 \%$ to $3 \%$ in the midlatitudes. LKBtype parameterizations (Fig. 18b) indicate negative values of (6), with the largest magnitude in the subtropics, coincident with the estimate given by Ledvina et al. (1993) for the Pacific. Smith's (1988) scheme (Fig. 18c) provides an intermediate estimate of (6), which is primarily negative. In general, we can point out that our estimates of sampling-to-classical ratios are probably the highest in comparison with other parameterizations. Our estimates may overestimate differences in the midlatitudes by $20 \%$ to $30 \%$, but they give similar differences in the Tropics.

Differences between sampling and classical estimates of heat fluxes can have profound implications for the evaluation of meridional heat transport (MHT), which is considered to be a key parameter of oceanic climate variability. To evaluate MHT, we computed shortwave radiation and longwave radiation with the parameterization of Malevsky et al. (1992). Details of the Malevsky et al. (1992) radiation schemes are given in Gulev (1995a), where they are compared with Reed (1977) and Dobson and Smith (1988). Radiation fluxes have the effect of an additive constant in our experiment and cannot change differences between the sampling and classical estimates of MHT. Then the estimates of the net radiation were combined with sampling and classical estimates of sensible and latent heat fluxes computed using the Ariel et al. (1981), Liu et al. (1979), and Smith (1988) methods. Figure 19 shows the results of these critical examinations. MHT estimates, which come out of the use of the Liu et al. (1979) and Smith (1988) schemes, are very close to each other, and thus we show in Fig. 19 only the curves computed with the Liu et al. (1979) and Ariel et al. (1981) schemes. We avoid here discussion of the reliability of climatological MHT, computed from sampling fluxes and presented in Fig. 19. The interested reader can find debates on this problem in Isemer et al. (1989), Oberhuber (1988), Gulev (1995a), and other articles. We will just point out that both sampling estimates computed using Ariel et al. (1981) and Liu et al. (1979) do not indicate dramatic differences with other heat balance and direct oceanographical estimates. Uncertainty of MHT results from the integration of latitudinal error in the net heat flux estimate and propagates rather fast from the north to the equator, giving for, say, $10 \mathrm{~W} \mathrm{~m}^{2}$ latitudinal uncertainty in the net sea-air flux nearly $0.8-\mathrm{PW}$ uncertainty in cross-equatorial MHT in the Atlantic and uncertainty that is twice as large in the Pacific (Talley 1984). We show in Fig. 19 uncertainty estimates from Gulev (1995a), which are higher than errors given by Lamb and Bunker (1982), but slightly smaller than those of Isemer et al. (1989). When we use classical estimates of fluxes, MHT decreases very sharply and, for the Ariel et al. (1981) parameterization, has already become a negative southward flux at $30^{\circ} \mathrm{N}$ (Fig. 19), in disagreement with all known computations of meridional heat fluxes. For the Liu et al. (1979) and Smith (1988) schemes, the departure of the classical estimate from the sampling estimate is not so large, 
Ariel et al. (1981)

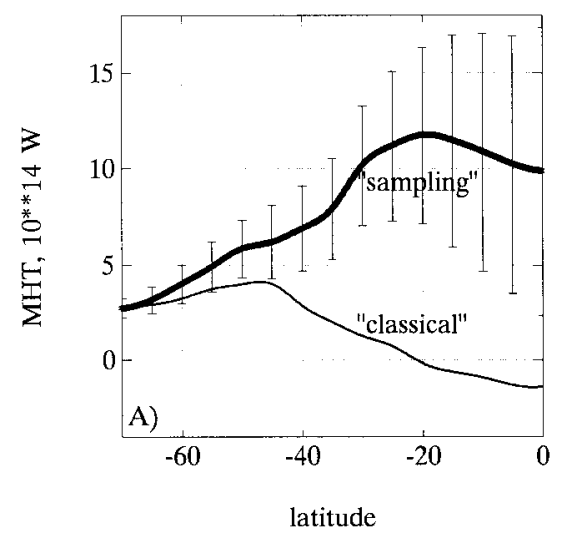

Liu et al. (1979)

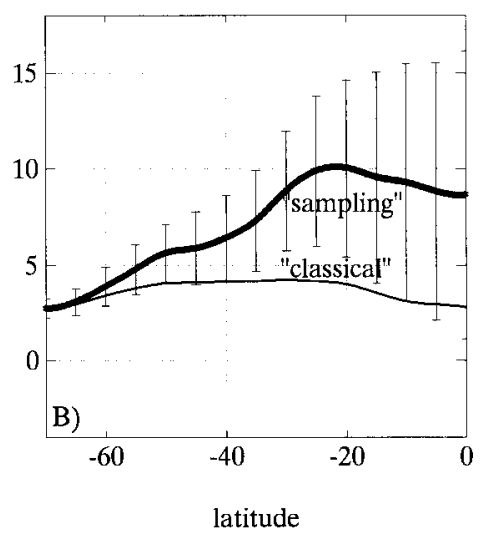

FIG. 19. Estimates of climatological meridional heat transport, based on sampling (bold line) and classical (thin line) estimates ( $5^{\circ}$ averaging) of sensible and latent heat fluxes, computed with the (a) Ariel et al. (1981) and (b) Liu et al. (1979) parameterizations. Error bars correspond to the uncertainties of MHT estimates.

but even this is smaller than the uncertainty bounds within the latitudinal belt of $10^{\circ}-35^{\circ} \mathrm{N}$. Differences between sampling and classical estimates of MHT are larger than differences between sampling MHT estimates computed with different transfer coefficients (Fig. 19).

Oberhuber (1988) used for the same 1950-79 period COADS MSTG data, which were smoothed by Wright (1988) and had an actual spatial resolution of approximately $4^{\circ}$ to $5^{\circ}$. He obtained at first very unreliable MHT estimates using Large and Pond's (1982) parameterization. He then increased the Charnock constant in the Large and Pond (1982) scheme to 0.032, nearly twice all known values of this parameter (Smith 1988). With this modified parameterization, he obtained an MHT that was still smaller then other estimates in the North Atlantic and indicated a maximum in the subtropics of about 0.6 PW. This estimate shows that such an increase of the Charnock constant has the effect of a $15 \%$ to $35 \%$ increase in transfer coefficients. Comparison of Oberhuber's (1988) coefficients with others schemes gives remarkably higher values than in other parameterizations (Kent and Taylor 1995). We have to note here that Oberhuber's (1988) shortwave radiation is from $3 \%$ to $8 \%$ smaller than other estimates for the North Atlantic. Thus, to achieve a reasonable MHT, Oberhuber's (1988) correction of the Large and Pond (1982) scheme should be even stronger. Taking into account the classical approach, used by Oberhuber (1988), the resulting differences in the transfer coefficients $(10 \%$ to $40 \%$ ) give a rough estimate of the sampling-to-classical ratio. It is difficult to discuss the spatial variability of this ratio, but the mean value is comparable with those obtained in our study.

Acknowledgments. This study was partially done during my periodical work at IFM (Kiel) in 1994 and 1995.
I appreciate the support of Prof. Dr. L. Hasse and constructive discussions with him. Discussions during the WCRP Workshop on Air-Sea Fluxes (ECMWF 1995) greatly helped to improve this paper. Thanks go to Peter Taylor and Glenn White, who organized this workshop and invited me to participate. I am especially thankful to Glenn White for his editorial assistance and to three anonymous reviewers for their helpful comments and suggestions. COADS data were made available by courtesy of Steve Worley of NCAR (Boulder, Colorado) and Hans-Joerg Isemer of GKSS (Geesthacht, Germany). This study is supported by Deutsche Forschungsgemeinscaft, Sonderforschungsbereich SFB 133, and the Ministry of Science and Technology of the Russian Federation.

\section{REFERENCES}

Adamec, D., and R. L. Elsbery, 1984: The use of mean atmospheric forcing in an ocean mixed-layer model. J. Phys. Oceanogr., 14, 1670-1676.

Ariel, N. Z., R. S. Bortkovskiy, S. P. Malevsky, and A. V. Murashova, 1981: Sensible, latent and momentum fluxes calculations over the sea. Methodical Comments, Main Geophysical Observatory, Leningrad, Russia, 55 pp. [Available from Main Geophysical Observatory, Karbysheva Str. 7, St. Petersburg, Russia.]

Bane, J. M., and K. E. Osgood, 1989: Wintertime air-sea interaction processes across the Gulf Stream. J. Geophys. Res., 94 (C8), $10755-10772$.

Bell, G. D., and L. F. Bosart, 1989: A 15-year climatology of Northern Hemisphere $500 \mathrm{mb}$ closed cyclone and anticyclone centers. Mon. Wea. Rev., 117, 2142-2162.

Bendat, J. S., and A. G. Piersol, 1966: Measurement and Analysis of Random Data. J. Wiley and Sons, 390 pp.

Blanc, T. V., 1985: Variation of bulk-derived surface flux, stability, and roughness due to the use of different transfer coefficient schemes. J. Phys. Oceanogr., 15, 650-669.

Bortkovskiy, R. S., 1983: Atmosphere-Ocean Heat and Moisture Exchange at Storm Conditions. Gidrometeouzdat, 160 pp.

Bottomley, M., C. K. Folland, J. Hsiung, R. E. Newell, and D. E. 
Parker, 1990: Global Ocean Surface Temperature Atlas. The Meteorological Office, 20 pp. plus 313 figures.

Budyko, M. I., 1963: Atlas of Heat Balance of the Earth. Academic Sciences of the USSR, $69 \mathrm{pp}$.

— 1974: Climate and Life. International Geophysical Series, Vol. 18, Academic Press, 508 pp.

Bunker, A. F., 1976: Computations of surface energy flux and annual air-sea interaction cycles of the North Atlantic Ocean. Mon. Wea. Rev., 104, 1122-1140.

— H. Charnock, and R. A. Goldsmith, 1982: A note on the heat balance of the Mediterranean and Red Seas. J. Mar. Res., 40 (Suppl.), 73-84.

Cardone, J. S., J. G. Greenwood, and M. A. Cane, 1990: On trends in historical marine wind data. J. Climate, 3, 113-127.

Cayan, D., 1992a: Variability of latent and sensible heat fluxes estimated using bulk formulae. Atmos.-Ocean, 30, 1-42.

, 1992b: Latent and sensible heat flux anomalies over the northern oceans: The connection to monthly atmospheric circulation. J. Climate, 5, 354-369.

,$- 1992 \mathrm{c}$ : Latent and sensible heat flux anomalies over the northern oceans: Driving the sea surface temperature. J. Phys. Oceanogr., 22, 859-881.

Claussen, M., 1990: Area averaging of surface fluxes in a neutrally stratified, horizontally inhomogeneous atmospheric boundary layer. Atmos. Environ., 24A, 1349-1360.

— 1991: Estimation of areally-averaged surface fluxes. Bound.Layer Meteor., 54, 387-410.

Colucci, S. J., 1976: Winter cyclone frequencies over the eastern United States and adjacent western Atlantic, 1964-1973. Bull Amer. Meteor. Soc., 57, 548-553.

da Silva, A. M., C. C. Young, and S. Levitus, 1994: Atlas of Surface Marine Data 1994. Vol. 2, National Oceanic and Atmospheric Administration, $419 \mathrm{pp}$

Diaz, H. F., X. Quan, and C. Fu, 1995: Marine surface wind changes during 1978-1992: An estimation based on COADS. Proc. Int. COADS Winds Workshop, Kiel, Germany, NOAA-ERL, IFM, $48-67$.

Dobson, F., and S. D. Smith, 1988: Bulk model of solar radiation at sea. Quart. J. Roy. Meteor. Soc., 114, 165-182.

Dyer, A. J., 1974: A review of flux-profile relationships. Bound.-Layer Meteor., 7, 363-372.

Efimov, V. V., N. A. Timofeev, I. V. Kurzeevsky, and E. N. Sychov, 1985: The estimate of the coefficients of the heat and moisture transfer between the ocean and atmosphere. Physics of the atmosphere and the ocean. Izv. Acad. Sci. USSR, 21, 735-743.

Esbensen, S. K., and V. Kushnir, 1981: The heat budget of the global oceans: An atlas based on estimates from marine surface observations. Oregon State University Climatic Research Institute Rep. 29, 27 pp. plus 188 figures. [Available from Oregon State University, Corvallis, OR 97331-2709.]

— , and R. W. Reynolds, 1981: Estimating monthly averaged airsea transfers of heat and momentum using the bulk aerodynamic method. J. Phys. Oceanogr., 11, 457-465.

Fissel, D. V., S. Pond, and M. Miyake, 1977: Computation of surface fluxes from climatological and synoptic data. Mon. Wea. Rev. $105,26-36$

Friehe, C. A., and K. F. Schmitt, 1976: Parameterization of air-sea interface fluxes of sensible heat and moisture by the bulk aerodynamic formulas. J. Phys. Oceanogr., 6, 801-809.

Garstang, M., 1965: Distribution and mechanism of energy exchange between the tropical oceans and the atmosphere. Dept. of Meteorology, The Florida State University Rep. DA-AMC-28-04364-05, 46 pp. [Available from The Florida State University, Tallahassee, FL 32306-3041.]

Gavrilin, B. L., and A. S. Monin, 1969: On calculations of climatic correlations, using numerical atmospheric models. Izv. Acad. Sci. USSR, Atmos. Oceanic Phys., 6, 659-665.

Gleckler, P. J., and B. Weare, 1995: Uncertainties in Global Ocean surface heat flux climatologies derived from ship observations.
PCMDI Rep. 26, 39 pp. [Available from PCMDI, Livermore, CA 94551.]

Gulev, S. K., 1994: Influence of space-time averaging on the oceanatmosphere exchange estimates in the North Atlantic midlatitudes. J. Phys. Oceanogr., 24, 1236-1255.

_- 1995a: Long-term variability of sea-air heat transfer in the North Atlantic Ocean. Int. J. Climatol., 15, 825-852.

- 1995b: Comparison of COADS winds with SNMC climatology and instrumental measurements in the North Atlantic. Proc. Int. COADS Winds Workshop, Kiel, Germany, NOAA-ERL, IFM, $121-131$

—, and V. V. Ukrainsky, 1989: The role of different time-scales in ocean-atmosphere energy exchange processes. Izv. Acad. Sci. USSR, Atmos. Oceanic Phys., 25, 675-687.

_—, and J. Tonkacheev, 1994: On the parameterization of sea-air interaction over SST fronts in the North Atlantic. Air-Sea Interface, M. A. Donelan, W. H. Hui, and W. J. Plant, Eds., University of Toronto Press, 20-29.

Hanawa, K., and Y. Toba, 1987: Critical examination of estimation methods of long-term mean air-sea heat and momentum transfers. Ocean-Air Int., 1, 79-93.

Hasse, L., 1970: On the determination of vertical transport of momentum and heat in the atmospheric boundary layer at sea. School Oceanography, Oregon State University, Tech. Rep. 188, $55 \mathrm{pp}$. [Available from Oregon State University, Corvallis, OR 97331-2709.]

- , and R. Lindau, 1997: The COADS Climate Atlas of the Atlantic. Springer-Verlag, in press.

Hastenrath, S., 1980: Heat budget of tropical ocean and atmosphere. J. Phys. Oceanogr., 10, 159-170.

— and Eastern Pacific Oceans. University of Wisconsin Press, 104 pp.

Hsiung, J., 1985: Estimates of global oceanic meridional heat transport. J. Phys. Oceanogr., 15, 1405-1413.

Husby, D. M., 1980: A comparison of surface heat flux estimates from ocean weather station $\mathrm{V}$ and merchant vessels in its vicinity in the western North Pacific region, 1956-1970. J. Phys. Oceanogr., 10, 971-975.

Isemer, H.-J., 1995: Trends in marine surface wind speed: Ocean Weather Stations versus Voluntary Observing Ships. Proc. Int. COADS Winds Workshop, Kiel, Germany, NOAA-ERL, IFM, $68-84$

— and L. Hasse, 1985: The Bunker Climate Atlas of the North Atlantic Ocean. Vol. 1, Observations, Springer-Verlag, 218 pp.

_ Ocean. Vol. 2, Air-Sea Interactions, Springer-Verlag, $252 \mathrm{pp}$.

_ _ J. Willebrand, and L. Hasse, 1989: Fine adjustment of large scale air-sea energy flux parameterizations by direct estimates of ocean heat transport. J. Climate, 2, 1173-1184.

Josey, S. A., E. C. Kent, and P. K. Taylor, 1995: Seasonal variations between sampling and classical mean turbulent heat flux estimates in the eastern North Atlantic. Ann. Geophys., 13, 10541064.

Kent, E. C., and P. K. Taylor, 1995: A comparison of sensible and latent heat flux estimates for the North Atlantic Ocean. J. Phys. Oceanogr., 25, 1530-1549.

— B. S. Truscott, P. K. Taylor, and J. S. Hopkins, 1991: The accuracy of ship's meteorological observations. Results of the VSOP-NA. Marine meteorology and related oceanographic activities. Rep. 26, WMO/TD-No. 455, 86 pp. [Available from Commission for Marine Meteorology, \% WMO, CP2300, 1211, Geneva 2, Switzerland.]

— , P. K. Taylor, B. S. Truscott, and J. S. Hopkins, 1993: The accuracy of voluntary observing ships meteorological observations-results of the VSOP-NA. J. Atmos. Oceanic Technol., 10, 591-608.

Kondo, J., 1972: Applicability of micrometeorological transfer coefficient to estimate the long-period means of fluxes in air-sea interface. J. Meteor. Soc. Japan, 50, 570-576. 
1975: Air-sea bulk transfer coefficients in diabatic conditions. Bound.-Layer Meteor., 9, 91-112.

Kraus, E. B., and R. E. Morrison, 1966: Local interactions between the sea and the air at monthly and annual time scales. Quart. J. Roy. Meteor. Soc., 92, 114-127.

Lamb, P. J., and A. F. Bunker, 1982: The annual march of the heat budget of the North and tropical Atlantic Oceans. J. Phys. Oceanogr., 12, 1388-1409.

Lander, M., J. C. Sadler, J. Maliekal, and A. Hori, 1989: Tropical wind stress from time-averaged winds. J. Appl. Meteor., 28, 904912.

Large, W. G., and S. Pond, 1981: Open ocean momentum flux measurements in moderate to strong winds. J. Phys. Oceanogr., 11, 324-336.

, and - 1982: Sensible and latent heat fluxes over the ocean. J. Phys. Oceanogr., 12, 463-482.

Larin, D. A., and G. N. Panin, 1985: The impact of correlation between meteorological parameters on the estimates of evaporation and heat exchange over the Kaspy Sea. Water Resour. Res., 5, 68-75.

Lau, N.-C., 1988: Variability of the observed midlatitude storm tracks in relation to low-frequency changes in the circulation pattern. J. Atmos. Sci., 45, 2718-2743.

Ledvina, D. L., G. S. Young, R. A. Miller, and C. W. Fairall: 1993 The effect of averaging on bulk estimates of heat and momentum fluxes for the tropical western Pacific Ocean. J. Geophys. Res., 98, 20211-20217.

Legler, D., 1991: Errors in five-day mean surface wind and temperature conditions due to inadequate sampling. J. Atmos. Oceanic. Technol., 8, 705-712.

Lindau, R., H.-J. Isemer, and L. Hasse, 1990: Towards time-dependent calibration of historical wind observations at sea. Trop. OceanAtmos. Newslett., 54, 7-12.

Liu, W. T., K. B. Katsaros, and J. A. Businger, 1979: Bulk parameterization of air-sea exchanges of heat and water vapor including the molecular constraints at the interface. J. Atmos. Sci., 36, $1722-1735$.

Mahrt, L., 1987: Grid-averaged surface fluxes. Mon. Wea. Rev., 115, $1550-1560$.

Malevsky, S. P., G. V. Girduk, and B. Egorov, 1992: Radiation Balance of the Ocean Surface. Hydrometeoizdat, $148 \mathrm{pp}$.

Marsden, R. F., and S. Pond, 1983: Synoptic estimates of air-sea fluxes. J. Mar. Res., 41, 349-373.

Mason, P. J., 1988: The formation of areally-averaged roughness lengths. Quart. J. Roy. Meteor. Soc., 114, 399-420.

Morrissey, M. L., and J. A. Maliekal, 1995: Standard error estimation of COADS monthly mean winds. Proc. Int. COADS Winds Workshop, Kiel, Germany, NOAA-ERL, IFM, 165-170.

Oberhuber, J. M., 1988: An atlas based on COADS data set: The budget of heat, buoyancy and turbulent kinetic energy at the surface of the Global Ocean. MPI Rep. 15, 199 pp. [Available from MPI, Bundesstrasse 55, D-20146 Hamburg, Germany.]

Paulson, C. A., 1970: The mathematical representation of wind speed and temperature profiles in the unstable atmospheric surface layer. J. Appl. Meteor., 9, 857-861.

Peterson, E. W., and L. Hasse, 1987: Did the Beaufort scale or the wind climate change? J. Phys. Oceanogr., 17, 1071-1074.

Pond, S., D. B. Fissel, and C. A. Paulson, 1974: A note on bulk aerodynamic coefficients for sensible heat and moisture fluxes. Bound.-Layer Meteor., 6, 333-339.

Ramage, C. S., 1984: Can shipboard measurements reveal secular changes in tropical air-sea heat flux? J. Climate Appl. Meteor., 23, 187-193

Reed, R. K., 1977: On estimating insolation over the ocean. J. Phys. Oceanogr., 7, 482-485.

_ 1985: An estimate of the climatological heat fluxes over the tropical Pacific Ocean. J. Climate Appl. Meteor., 24, 833-840.

Reitan, C. H., 1974: Frequencies of cyclones and cyclogenesis for North America, 1951-1970. Mon. Wea. Rev., 102, 861-868.
Robinson, G. D., 1966: Another look at some problems of the airsea interface. Quart. J. Roy. Meteor. Soc., 92, 451-465.

Roebber, P. J., 1989: On the statistical analysis of cyclone deepening rates. Mon. Wea. Rev., 117, 2293-2298.

Saunders, P. M., 1976: On the uncertainty of wind stress curl calculations. J. Mar. Res., 34, 155-160.

Schinke, H., 1993: On the occurrence of deep cyclones over Europe and the North Atlantic in the period 1930-1991. Beitr. Phys. Atmos., 66, 223-237.

Simmonds, I., and M. Dix, 1989: The use of mean atmospheric parameters in the calculation of modeled mean surface heat fluxes over the world's oceans. J. Phys. Oceanogr., 19, 205-215.

Slutz, R. J., S. J. Lubker, J. D. Hiscox, S. D. Woodruff, R. L. Jenne, D. H. Joseph, P. M. Steurer, and J. D. Elms, 1985: Comprehensive Ocean-Atmosphere Data Set: Release 1. NOAA Environmental Research Laboratory, CRP, Boulder, CO, 268 pp. [Available from NCAR, P. O. Box 3000, Boulder, CO 80303-3328.]

Smith, S. D., 1980: Wind stress and heat flux over the ocean in gale force winds. J. Phys. Oceanogr., 10, 709-726.

— 1988: Coefficients for sea surface wind stress, heat flux, and wind profiles as a function of wind speed and temperature. $J$. Geophys. Res., 93, $15467-15472$.

_ , and E. G. Banke, 1975: Variation of the sea surface drag coefficient with wind speed. Quart. J. Roy. Meteor. Soc., 101, 665673.

Staneva, J. V., E. V. Stanev, and N. H. Rachev, 1995: Heat balance estimates using atmospheric analysis data: A case study for the Black Sea. J. Geophys. Res., 100(C9), 18 581-18596.

Talley, L. D., 1984: Meridional heat transport in the Pacific Ocean. J. Phys. Oceanogr., 14, 231-241.

Thompson, K. R., R. F. Marsden, and D. G. Wright, 1983: Estimation of low-frequency wind stress fluctuations over the open ocean. J. Phys. Oceanogr., 13, 1003-1011.

von Storch, H., J. Guddal, K. A. Iden, T. Jonsson, J. Perlwitz, M. Reistad, J. de Ronde, H. Schmidt, and E. Zorita, 1993: Changing statistics of storms in the North Atlantic. Max-Plank-Institut für Meteorologie Rep. 116, 19 pp. [Available from MPI, Bundesstrasse 55, D-20146 Hamburg, Germany.]

Ward, M. N., 1992: Provisionally corrected surface wind data, worldwide ocean-atmosphere surface fields, and Sahelian rainfall variability. J. Climate, 5, 454-475.

Weare, B. C., 1989: Uncertainties in estimates of surface heat fluxes derived from marine reports over the tropical and subtropical oceans. Tellus, 41A, 357-370.

, and P. T. Strub, 1981: The significance of sampling biases on calculated monthly mean oceanic surface heat fluxes. Tellus, 33, 211-224.

,-- , and M. D. Samuel, 1981: Annual mean surface heat flux in the tropical ocean. J. Phys. Oceanogr., 11, 705-717.

Whittaker, L. M., and L. H. Horn, 1981: Geographical and seasonal distribution of North American cyclogenesis, 1958-1977. Mon. Wea. Rev., 109, 2312-2322.

Woodruff, S. D., S. J. Lubker, K. Wolter, S. J. Worley, and J. D. Elms, 1993: Comprehensive Ocean-Atmosphere Data Set (COADS) Release 1a: 1980-92. Earth Syst. Monitor, 4, 1-8.

Wright, D. G., and K. R. Thompson, 1983: Time averaged forms of nonlinear stress low. J. Phys. Oceanogr., 13, 341-345.

Wright, P., 1988: An atlas based on the COADS data set: Fields of mean wind, cloudiness and humidity at the surface of the global ocean. Max-Plank-Institut für Meteorologie Rep 14. [Available from MPI, Bundesstrasse 55, D-20146 Hamburg, Germany.]

Yau, M. K., and M. Jean, 1989: Synoptic aspects and physical processes in the rapidly intensifying cyclone of 6-8 March 1986. Atmos.-Ocean, 27, 59-86.

Zhang, G. J., 1995: Use of monthly mean data to compute surface turbulent fluxes in the tropical Pacific. J. Climate, 8, 3084-3090.

Zishka, K. M., and P. J. Smith, 1980: The climatology of cyclones and anticyclones over North America and surrounding ocean environs for January and July, 1950-1977. Mon. Wea. Rev., 108, 387-401. 